\title{
Partisan Gaps in Political Information and Information-Seeking Behavior: Motivated Reasoning or Cheerleading?
}

\author{
Erik Peterson \\ Texas A\&M University \\ Department of Political Science \\ 4348 TAMU \\ College Station, TX 77843 \\ erik.peterson@tamu.edu
}

\author{
Shanto Iyengar \\ Stanford University \\ Department of Political Science \\ Encina Hall West, Suite 100 \\ Stanford, CA 94305 \\ siyengar@stanford.edu *
}

Forthcoming at the American Journal of Political Science

\begin{abstract}
Do partisan disagreements over politically-relevant facts, and preferences for the information sources from which to obtain them, represent genuine differences of opinion or insincere cheerleading? The answer to this question is crucial for understanding the scope of partisan polarization. We test between these alternatives with experiments that offer incentives for correct survey responses and allow respondents to search for information before answering each question. We find that partisan cheerleading inflates divides in factual information, but only modestly. Incentives have no impact on partisan divides in information search; these divides are no different from those that occur outside the survey context when we examine web browsing data from the same respondents. Overall, our findings support the motivated reasoning interpretation of misinformation; partisans seek out information with congenial slant and sincerely adopt inaccurate beliefs that cast their party in a favorable light.
\end{abstract}

*We acknowledge with gratitude financial support provided by the Hewlett Foundation and a Facebook Integrity Foundational Research Project award. We also thank John Bullock, Jamie Druckman, Jennifer Jerit and Yusaku Horiuchi for their comments. 
Over the past three decades, heightened polarization has made partisanship increasingly influential in political life. Rank and file partisans now hold such harsh views of their opponents (Iyengar et al., 2012; Mason, 2018) that they avoid social interactions with out-party members (Huber and Malhotra, 2017; Iyengar et al., 2018). Partisan cues from polarized elites powerfully influence the candidate evaluations and policy views of their supporters (Levendusky, 2010; Druckman et al., 2013).

At the frontier of these developments is the intrusion of partisanship into the public's factual beliefs (for reviews, see Jerit and Zhao, ND; Bullock and Lenz, 2019; Flynn et al., 2017; Shapiro and Block-Elkon, 2008). A number of studies find that partisans disagree about politically-relevant facts on topics ranging from the performance of the economy (e.g., Bartels, 2002; Schaffner and Roche, 2017; Bisgaard and Slothuus, 2018) to the details of health care policy (e.g., Berinsky, 2017; Nyhan, 2010). These divides raise the possibility that misinformation undermines voters' ability to hold elected officials accountable (Kuklinski et al., 2000; Shapiro and Block-Elkon, 2008; Hochshild and Einstein, 2015).

We assess two competing interpretations of polarized responses to information questions. In one, partisan divides reflect genuine differences in factual beliefs. In this motivated reasoning account, polarization has strengthened partisans' willingness to ignore or counter-argue with credible facts that cast aspersions on their party or party leaders and, conversely, to uncritically accept false information that reflects favorably on their side (Gaines et al., 2007; Shapiro and Block-Elkon, 2008; Kraft et al., 2015).

A contrasting interpretation is that these divides reflect insincere partisan cheerleading in which partisans knowingly distort their responses to survey questions to signal support for their side (Prior et al., 2015; Bullock et al., 2015; Schaffner and Luks, 2018). In this view, partisans are in fact well informed, but prefer to act misinformed in surveys. In essence, the cheerleading account implies that the partisan divides over factual evidence measured in surveys are largely illusory. 
We use survey experiments that incentivize respondents to correctly answer factual knowledge questions to implement new tests for distinguishing between these competing accounts (for previous applications of this approach see Bullock et al., 2015; Prior et al., 2015). To understand the nature of partisan divides over politically-relevant facts, and preferences for the information sources from which to obtain them, we introduce three changes to the incentive-based experimental design used in earlier work.

First, while previous studies incentivize partisans to correctly answer questions about past political controversies (Bullock and Lenz, 2019; 339), we assess their responsiveness to incentives on highly salient controversies ongoing at the time we fielded our surveys. Second, we broaden the range of outcome variables to include partisan divides in information search. Before answering each information question, respondents selected one news report to read from a set of two partisan news sources, two non-partisan news sources, and an expert source. Information seeking behavior is no less subject to a cheerleading interpretation since, in the context of the typical unincentivized survey, partisans may support their party by expressing an affinity for co-partisan news sources they do not ordinarily use (see e.g., Prior, 2013; 114-115). Third, we validate our survey results by using behavioral web browsing data to compare the information search preferences of respondents in the survey to their real-world news consumption outside it.

Overall, our findings support motivated reasoning rather than the cheerleading interpretation of partisan divides in information and information seeking behavior. First, while incentives reduce partisan divides in information, substantial partisan gaps - on the order of 60 to 70 percent of the initial unincentivized divide - persist even when incentives are present (see also Berinsky, 2018). Second, the provision of incentives has no bearing on information selection. Partisans seek out information from co-partisan media sources to the same extent whether incentives are available or not. Moreover, the divides in information search we observe in the survey context mirror partisan divides in online news consumption 
registered by the same individuals outside the survey setting.

We next review previous studies of political misinformation and consider the debate over the appropriate interpretation of partisan divides over political facts. We then introduce and implement a research design that combines survey experiments regarding political misinformation with behavioral web-browsing data to consider partisan divides in information and information-seeking behavior.

\section{From "Dark Areas of Ignorance" to "Alternative Facts"}

Political scientists' interest in political knowledge dates back at least to the mid-twentieth century. Following the Second World War, surveys probing the depth of the public's political information revealed "dark areas of ignorance" (Kreisberg, 1949). Most Americans were unable to name prominent political figures or recognize current debates in the foreign or domestic policy arenas (Almond, 1950). These findings revived earlier debates over the implications of information deficits for representative democracy (Lippman, 1922).

This classic work on political knowledge, which reflected the assumptions of democratic theory, primarily focused on the distinction between the informed and the uninformed (Delli Carpini and Keeter, 1996). Only later did researchers consider the possibility that some respondents were misinformed (Kuklinski et al., 2000) and that incorrect answers to knowledge questions reflected partisan bias rather than simple ignorance.

In an influential paper, Bartels (2002) identified systematic partisan biases in answers to factual questions dating back to the 1980s. Despite significant improvements in inflation and unemployment over the eight years of the Reagan Presidency, Democrats offered generally pessimistic views of national economic conditions. Bartels concluded partisans' perceptions of the economy, rather than reflecting real-world conditions, showed "substantial partisan bias" (p. 136; see also Schaffner and Roche, 2016; Bisgaard, 2015). 
There are also partisan differences in consumer confidence (Mian et al., 2017; Enns et al. 2012) and awareness of policy initiatives pursued by incumbents (Gaines et al., 2007). These discrepancies are greater for topics on which the news media provides more extensive coverage, suggesting partisans selectively interpret media coverage (Jerit and Barabas, 2012; Schaffner and Roche, 2017; Kim and Kim, 2019). Note, however, that despite significant partisan gaps in economic perceptions and expectations, indicators of economic behavior (e.g. purchasing) showed no partisan differences (McGrath, 2017). This disconnect between attitudes and behavior is suggestive of the current controversies (described below) that surround explanations for misinformed survey responses.

Recent studies make clear that misinformation extends beyond questions of economic performance and policy to false claims about Barack Obama's religion and country of birth, conspiracy theories that the government had advance knowledge of the September 11th terrorist attacks, and beliefs about climate change (see e.g., Hochshild and Einstein, 2015; Flynn et al. 2017; Bullock and Lenz, 2019). Moreover, inaccurate beliefs are not limited to some fringe element of the electorate. On survey items we later examine in this study, partisan differences approach 50 percentage points on some matters related to misstatements made by Donald Trump, including widely publicized claims about illegal voting in the 2016 election and the alleged wiretapping of Trump Tower by the Obama Administration.

Before we proceed it is important to note that, even in contemporary politics, partisan divisions over political information are not always present. Graham (ND) and Roush and Sood (2019) conduct systematic assessments of political information and identify many topics with modest or non-existent partisan divides. At the same time, our preceding review establishes some issues on which Republicans and Democrats endorse different sets of facts. In what follows, we focus on these areas of intense partisan disagreement as they underlie concerns about the implications of political misinformation, represent an important setting for understanding the sincerity of the misinformation measured in surveys and have not been 
used in previous studies that provide monetary incentives for correctly answering political information questions.

\section{Motivated Reasoning and Misinformation}

What explains these partisan divides over facts? One common interpretation is that they stem from motivated reasoning. Psychologists have uncovered several information-processing heuristics including confirmatory bias and motivated skepticism (Lord et al., 1979; Kunda, 1990) that allow individuals to protect their identity from dissonant information. These biases in information processing are supplemented by other mechanisms that shape the information people encounter in the first place, in particular theories of cognitive consistency (Festinger, 1957) in which selective exposure limits the public's encounters to information at odds with their beliefs.

This motivated reasoning account is well-suited to explaining the adoption of partycongenial misinformation in contemporary politics (Taber and Lodge, 2013; Gaines et al., 2007; Kraft et al., 2015; Miller et al. 2016; Flynn et al., 2017). Rising elite polarization and growing antipathy towards the other political party have strengthened partisans' motivation to ignore credible facts that cast aspersions on their party or party leaders and, conversely, to accept false information that reflects favorably on their side. These tendencies are complemented by a high-choice information environment that creates an opportunity for partisans to screen out uncongenial information (Stroud, 2011; Iyengar and Hahn, 2009) and the availability of misinformation from political elites (e.g., Bisgaard and Slothuus, 2018). This is particularly relevant following the election of Donald Trump, a politician willing to make misleading and false claims on a regular basis. The current information environment thus creates multiple opportunities and incentives for partisans to accept misinformation.

Importantly for what follows, from this perspective the divides in political information 
that result from motivated reasoning are real and troubling. Individuals accept misinformation and go on to incorporate it into their future political decisions (see e.g., Thorson, 2016; Swire et al., 2017; Flynn and Krupnikov, 2019).

Before proceeding, we note that motivated reasoning is not the only mechanism through which the genuine adoption of factually inaccurate beliefs may occur. For instance, differential beliefs regarding source credibility and evidence quality may produce similar partisan divides through a process that does not depend on biased information processing (Druckman and McGrath, 2019). Our design does not let us distinguish motivated reasoning from these other processes. Such examinations remain an important topic for future work $\mathbb{1}$

\section{Misinformation as Partisan Cheerleading}

In contrast to the preceding account of motivated reasoning, in which partisan divides over facts are genuine, a recent alternative perspective suggests these divides are illusory. Under this account, typically referred to as partisan cheerleading (see e.g., Bullock and Lenz, 2019), partisans know the correct answer to knowledge questions, but prefer to offer an incorrect, party-congenial survey response to support their side (Prior et al., 2015; Bullock et al., 2015; Schaffner and Luks, 2018).

These contrasting interpretations of existing evidence have led scholars to develop research designs that can distinguish motivated reasoning from partisan cheerleading. As described below, one widely used approach is to provide financial incentives that reward respondents for accurate answers to information questions. To the extent partisan differences

\footnotetext{
${ }^{1}$ Our use of "motivated reasoning" to describe the process producing sincerely held inaccurate beliefs follows the vast misinformation literature in which motivated reasoning is identified as "the most useful framework for understanding misperceptions about politics" (Flynn, Nyhan and Reifler, 2017, 131; see also Miller et al., 2016).
} 
in information shrink or vanish when researchers incentivize respondents to provide accurate answers, it strengthens the interpretation that incorrect responses represent "cheerleading" rather than genuine misinformation.

In the first attempt to distinguish between these alternative accounts of misinformation, Lupia and Prior (2008) offered respondents one dollar per correct answer before asking a battery of 14 factual questions. Unfortunately, the questions generally lacked partisan valence, focusing instead on candidate issue positions and other matters relating to the 2004 election. Respondents incentivized to give accurate answers scored higher on information, however, the study did not examine the effects of incentives on partisan differences in information.

A second study, conducted in 2008 (Bullock et al., 2015), provided more persuasive evidence on the "corrective" impact of financial incentives. The partisan difference in information, which was substantial among respondents offered no incentive, fell by half among respondents informed that their chances of winning a 200 dollar gift certificate would increase with correct answers. In a follow-up study, the researchers offered respondents varying amounts of money (ranging from 10 cents to a dollar) for correct responses; as they expected, the partisan gap in information fell most dramatically in the highest payoff condition. Finally, another 2008 study (Prior et al., 2015) asked respondents about economic conditions under the Bush Administration and paid one dollar per each correct response. The partisan difference in correct responses fell substantially in the incentivized group, leading the authors to conclude that partisan bias in perceptions of economic conditions represents "an artifact of partisan consistency pressures" (p. 510).

Contrary to these studies, recent work on the acceptance of rumors (Berinsky, 2018) reaches the conclusion that incentives and related interventions designed to increase the accuracy of survey responses have little impact on strongly valenced partisan beliefs. In this study, incentives - operationalized using the time respondents would be required to spend on the survey rather than a direct monetary payment - did little to weaken Republicans' belief 
that former President Obama is a Muslim, or Democrats' willingness to state that members of the Bush Administration knew about the 9/11 attacks in advance. Across multiple studies that deployed three different techniques for boosting response accuracy, partisan differences in rumor acceptance did not change. Berinsky's conclusion? "Expressive responses to rumor questions from across the political spectrum are relatively rare. More generally, these results suggest that - contrary to the concerns raised by some scholars such as Bullock et al. (2015) - survey responses serve as a window into the underlying beliefs and true preferences of the mass public" (p. 213).

In summary, there is agreement that on many political information questions Democrats and Republicans gravitate to survey responses that cast their party in a favorable light. There is disagreement, however, over the meaning of these divides. Some scholars discount the evidence of considerable misinformation as an artifact, citing impression management objectives that motivate partisans to answer incorrectly. Others dispute this account, believing that misinformation is a genuine phenomenon rooted in polarization and the availability of biased information.

\section{Research Design}

We introduce a modified version of the experimental design previously used to identify the contribution of cheerleading to partisan divides on political misinformation. There are three stages to our modified incentive design. First, following earlier studies, we randomly assign survey respondents to either receive or not receive incentives for correctly answering political knowledge questions. In both the surveys we consider, these incentives were $\$ 0.50$ per question for a five-item information battery. Respondents assigned to receive incentives were informed of this before answering the information questions. In a point we later revisit when discussing the implications of our findings, this amount falls in between the incentive 
levels used in previous studies. It is less than those in study $1(\$ 1.00)$ and study $2(\$ 2.00)$ of Prior et al. (2015), but greater than the incentives in study 1 of Bullock et al. (2015), which provided a lottery entry worth approximately $\$ 0.17$, and some conditions of study 2 of Bullock et al. (2015), which varied incentive levels from $\$ 0.10$ to $\$ 1.00$.

The second stage of this design departs from earlier studies. Before answering each question, respondents selected a news article on the topic to read. They saw a menu of five information sources, each accompanied by an article headline, and selected one to view $\mathrm{L}^{2}$ They were then taken to a brief report (approximately two paragraphs in length) drawn from a real story on the topic available from that source.

While the specific sources varied across each survey item, the choice set remained consistent. In each case, respondents could choose to read information from one left-leaning source (i.e., MSNBC or Huffington Post), one right-leaning source (i.e., Fox News or Breitbart), one source with specialized expertise (e.g., excerpts from a Bureau of Labor Statistics press release in the case of a question about the unemployment rate), or from a pair of mainstream news sources (i.e., CNN, New York Times).

Finally, in the third stage, after reading the report they selected, respondents answered the political information question and also indicated how confident they were (ranging from "not at all sure" to "extremely sure") of their answer.

This design accomplishes two goals. First, the random assignment of incentives provides insight into the extent to which divides in factual beliefs are inflated by partisans knowingly providing incorrect, but party-congenial, answers to the questions. We assess this inflation by comparing the magnitude of the partisan divide across the treatment conditions. This element of the design allows us to extend prior studies of partisan cheerleading to a set of new hyper-partisan information items centered around controversies that were ongoing as we fielded our studies (we discuss the content of the information questions in the next section).

\footnotetext{
${ }^{2}$ Appendix A2 and A3 show how the news selection tasks appeared to respondents.
} 
Second, the information search component of our design allows us to move beyond previous work and consider whether the availability of incentives changes individuals' preferences for information sources. Of particular interest is the impact of incentives on partisan differences in news choice. We can observe whether partisan cheerleading applies not only to factual beliefs, but also to partisan selective exposure. Some past work suggests this possibility could occur if, in surveys, partisans feel pressure to express an affinity towards news sources associated with their side, but which they typically avoid when looking for accurate information in the real-world (e.g., Prior, 2013). Accordingly, this outcome yields important insight into the reputation of media outlets. If these reputations are weakly held and partisans knowingly trade off unbiased for biased news coverage in the unincentivized conditions, they should alter their search preferences in favor of unbiased sources when provided with incentives for correct answers.

The final piece of our research design is the ability to observe the news consumption of some survey respondents outside the survey context. While we discuss this feature of the study in more detail later, some survey respondents had previously installed an application that tracked their web browsing behavior. We can therefore compare the news choices they made in the survey with the choices that characterize their everyday web browsing behavior. This provides a rare opportunity to understand which, if any, of the experimental conditions in our survey corresponds with the naturally-occurring incentives for information acquisition that respondents face in the real world. While we refer to this real-world browsing data, at times, as a measure of information search, we note here these real-world media consumption choices reflect a mix of information acquisition, desire for congenial information and interest in the non-political material available from these media sources (see e.g., Stroud, 2011). 


\section{Data}

We collected data using this modified incentive design in two surveys administered by YouGov. These surveys use the firm's standard procedure of drawing a sample from its panel that is matched to the voting-age population on key demographic characteristics (e.g., Vavreck and Iyengar, 2011). The first, conducted in September 2018, had 1,000 respondents. The second, conducted in March 2019, had 1,700 respondents..$^{3}$ Because of their similar formats, we pool the surveys together for analysis, although in Appendix B we note the results are no different when we consider the surveys separately.

This matched sampling approach is also used in other academic surveys (e.g., the Cooperative Congressional Election Study). We note here that the unweighted sample used in our primary analysis is older and more highly educated than a nationally-representative sample would be (see Table A1 for demographic information). At the same time, there is little evidence this contributes to our findings, particularly as we see similar results in robustness checks that incorporate survey weights to correct for these deviations between our realized sample and nationally-representative targets (See Appendix B).

Our information items focused on several topics covered in prior studies of political misinformation (e.g., national economic conditions and climate change) as well as new questions bearing on inaccurate and controversial statements associated with President Trump. Table 1 displays the information items in the two surveys.

\footnotetext{
${ }^{3}$ While we do not incorporate this feature of the data into our current analysis, there was a panel structure to these surveys. 954 individuals completed both surveys.
} 
Table 1: Misinformation Items

\begin{tabular}{llll}
\hline Topic & Item & Incorrect Response & Party Valence \\
\hline $\begin{array}{l}\text { Climate Change } \\
\text { (Survey 1) }\end{array}$ & $\begin{array}{l}\text { The vast majority (over 90\%) of climate } \\
\text { scientists believe that global warming is } \\
\text { an established fact and that it is most } \\
\text { likely caused by man-made emissions }\end{array}$ & False & Republican \\
\hline $\begin{array}{l}\text { Cohen Plea } \\
\text { (Survey 2) }\end{array}$ & $\begin{array}{l}\text { Michael Cohen, Donald Trump's personal } \\
\text { lawyer, pleaded guilty to fraud and illegal } \\
\text { campaign finance charges in August 2018 }\end{array}$ & False & Republican \\
\hline $\begin{array}{l}\text { Firearm Sales } \\
\text { Survey 2) }\end{array}$ & $\begin{array}{l}\text { 40\% of firearm sales in the US occur } \\
\text { without a background check }\end{array}$ & True & Democratic \\
\hline $\begin{array}{l}\text { Immigrant Crime } \\
\text { (Survey 1) }\end{array}$ & $\begin{array}{l}\text { Illegal immigrants commit violent crime } \\
\text { at a significantly higher rate than legal } \\
\text { American citizens }\end{array}$ & True & Republican \\
\hline $\begin{array}{l}\text { Obama Wiretap } \\
\text { Survey 1 \& 2) }\end{array}$ & $\begin{array}{l}\text { Former President Obama ordered } \\
\text { wire taps on Donald Trump's phones }\end{array}$ & True & Republican \\
\hline $\begin{array}{l}\text { Voter Fraud } \\
\text { (Survey 1 \& 2) }\end{array}$ & $\begin{array}{l}\text { Millions of illegal votes were cast } \\
\text { in the 2016 presidential election. }\end{array}$ & True & Republican \\
\hline $\begin{array}{l}\text { Unemployment } \\
\text { (Survey 1 \& 2) }\end{array}$ & $\begin{array}{l}\text { Compared to January 2017, has the level } \\
\text { stayed the same, or decreased? }\end{array}$ & $\begin{array}{l}\text { Increased OR } \\
\text { Remained the samene }\end{array}$ & Democratic \\
\hline
\end{tabular}

As Table 1 shows, we include items with different partisan valence, which we define as the directional motivation to provide party-congenial, inaccurate answers. Depending on the item, these pressures can apply to either Democrats or Republicans. The items regarding unemployment under the Trump administration and firearm sales push Democrats toward the incorrect answer. Since most of the remaining items address inaccurate statements by President Trump (e.g., his unsubstantiated claim of widespread voter fraud in the 2016 election), the pressure to treat these statements as accurate is concentrated among Republicans.

\section{Hypotheses}

Motivated reasoning and cheerleading are two alternative explanations for partisan differences in beliefs about current issues and events. Proponents of cheerleading argue that polarization creates short-term psychic rewards for partisans to offer knowingly incorrect 
responses to knowledge questions, even as it does not induce genuine belief in these partycongenial falsehoods. In contrast, discussions of motivated reasoning posit that party polarization is so intense that partisans accept claims that cast their party in a favorable light, even when the claims are at odds with the facts.

Our design permits us to compare these competing hypotheses using three tests. First, we assess the impact of financial incentives on partisan divides in answers to the political knowledge questions. If cheerleading is the predominant explanation for these differences, providing incentives should markedly weaken the partisan divide, as partisans would be expected to revert to their "true" state of knowledge when responding. On the other hand, if the motivated reasoning hypothesis holds, then misinformation is genuine and incentives should have minimal effects on partisan divides across these items.

Second, we apply the same logic to assess the effect of financial incentives on respondents' information-seeking behavior, and specifically, whether the presence of incentives encourages the use of unbiased or non-partisan news providers (versus co-partisan news sources). Again, if cheerleading is at work, we would expect reliance on partisan sources to be weakened among incentivized respondents, while the motivated reasoning account predicts no differences in information preferences across the experimental conditions.

Finally, we were able to directly compare news preferences exhibited in both the incentivized and non-incentivized conditions with naturally occurring news consumption. This was possible because we recruited a subset of our experimental participants from an online panel whose survey responses could be linked to their daily web browsing behavior. Here, the cheerleading account predicts greater consistency of news preferences between the incentivized condition and everyday browsing behavior, while the non-incentivized condition should deviate from both the incentivized condition and everyday behavior (precisely because in the non-incentivized condition cheerleading is operative). On the other hand, the motivated reasoning paradigm leads us to expect the incentivized and non-incentivized conditions 
will be similar to each other each other and to naturally occurring browsing behavior.

\section{Results: Partisan Divides in Information}

We begin by documenting partisan divides in information among participants in the unincentivized condition of our surveys. For each item, Table 2 displays the share of Democrats providing the correct answer, the share of Republicans providing the correct answer and the divide between these groups, operationalized as the absolute value of the difference between the share answering correctly in each group. The items are sorted from those with the most pronounced gaps between parties to those with the smallest gaps.

Table 2: Partisan Information Divides in Unincentivized Conditions

\begin{tabular}{rlrrr}
\hline & Topic & Share Correct (Dem) & Share Correct (Rep) & Partisan Divide \\
\hline 1 & Immigrant Crime (Survey 1) & 0.97 & 0.45 & 0.52 \\
2 & Voter Fraud (Survey 2) & 0.86 & 0.38 & 0.48 \\
3 & Obama Wiretap (Survey 2) & 0.98 & 0.53 & 0.45 \\
4 & Voter Fraud (Survey 1) & 0.92 & 0.49 & 0.43 \\
5 & Obama Wiretap (Survey 1) & 0.98 & 0.58 & 0.40 \\
6 & Firearm Sales (Survey 2) & 0.22 & 0.56 & 0.34 \\
7 & Climate Change (Survey 1) & 0.96 & 0.63 & 0.33 \\
8 & Cohen Plea (Survey 2) & 0.93 & 0.80 & 0.13 \\
9 & Unemployment (Survey 1) & 0.74 & 0.85 & 0.11 \\
10 & Unemployment (Survey 2) & 0.72 & 0.80 & 0.08 \\
\hline
\end{tabular}

Table 2 reveals substantial partisan divides across the items we consider. Notably, the smallest divides occur on the misinformation items that overlap with those included in earlier studies that find partisan cheerleading to explain a substantial proportion of the partisan divide over political information (i.e., the items regarding unemployment). This speaks to the particularly divisive nature of the new items we examine, which derive from controversies that were ongoing as the surveys were fielded.

To consider how the availability of incentives affected these substantial partisan divides, we stack each respondent's answers to the political information questions to conduct a pooled 
analysis of these different items. We follow previous studies (e.g., Bullock et al., 2015) and standardize the direction of these outcome measures. Specifically, we code responses so that the information items are oriented in a similar manner, with the answer that is partycongenial for Democrats always receiving the higher value. So, for the items where the misinformed answer is party-congenial for Democrats, incorrect answers are coded as one and correct answers are coded as zero. This is reversed on items where the misinformed answer is party-congenial for Republicans. Here incorrect answers are coded as zero and correct answers are coded as one. This allows us to readily interpret partisan differences that emerge across these different items.

Respondents were not provided with a "Don't know" option across these items, meaning they had to provide some form of response. In this respect our study is similar to the first study in Bullock et al. (2015) and Prior et al. (2015), but departs from the conditions in the second study of Bullock et al. (2015) in which partisan divides over fact decline when a "Don't know" option is made available. However, in later sections we also incorporate a measure of response certainty that allows us to isolate firmly-held inaccurate beliefs.

We use the following specification, where $i$ indexes respondents and $k$ indexes the different questions, to examine partisan differences in political information in the baseline and incentive treatment conditions:

$$
\begin{aligned}
\text { Information }_{i k} & =\beta_{0}+\beta_{1} \text { Democrat }_{i}+\beta_{2} \text { Incentive Treatment }_{i} \\
& +\beta_{3} \text { Democrat }_{i} \times \text { Incentive Treatment }_{i}+\alpha_{k}+\epsilon_{i k}
\end{aligned}
$$

Democrat is a binary variable with a value of one for Democrats and zero for Republicans. We include those who "lean" toward one of the parties with the party they are close to. Because they do not face directional pressures in the same way as partisans, we exclude 
"pure" independents from the analysis.t The coefficient on this variable $\left(\beta_{1}\right)$ indicates the magnitude of the partisan informational divide in the baseline, unincentivized condition. The interaction between partisanship and the incentive treatment $\left(\beta_{3}\right)$ captures the impact of the incentive treatment on this divide. We also include fixed effects for each survey item $\left(\alpha_{k}\right)$ and cluster standard errors by respondent to account for the multiple observations per respondent and because we assigned treatments at the respondent level.

Table 3 displays the results of this analysis. The first column considers all partisan respondents. There is a substantial partisan divide (.32) over political information (95\% Confidence Interval $[0.31,0.33])$. Since the information items have a dichotomous metric, the observed divide amounts to roughly one-third the range of the outcome variable.

Moving to the other coefficient of interest, the interaction between partisanship and the incentive treatment is negative and statistically significant $(-0.10,95 \%$ Confidence Interval $[-.12,-.08])$. Incentives reduce the partisan divide to two-thirds of the magnitude in the unincentivized conditions. Consistent with earlier work, this amounts to some evidence of cheerleading (e.g., Bullock et al., 2015, Prior et al., 2015).

The next three columns examine this pattern across three subsets of the data: strong partisans (Column 2), information items for which Democrats were motivated to answer incorrectly (Column 3), and information items where the incorrect answer was party-congenial for Republicans (Column 4). There is some minor variation in the initial magnitude of these partisan divides across these different specifications, but the effect of incentives remains similar and statistically significant effect across all three.

While the partisan gap in information closes due to incentives, it is by no means eliminated. Large partisan divisions remain in the incentivized condition. This means that cheerleading alone is an insufficient explanation for the partisan information divide. In our primary specification from Column 1 that includes all items and all partisan respondents, the

\footnotetext{
${ }^{4}$ See Appendix B.2 for the results among this group
} 
Table 3: Effect of Incentives on Partisan Information Divide

\begin{tabular}{lrrrr}
\hline & All Partisans & Strong Partisans & Dem-Valenced & Rep-Valenced \\
\hline (Intercept) & $0.64^{*}$ & $0.59^{*}$ & $0.56^{*}$ & $0.59^{*}$ \\
& $(0.02)$ & $(0.02)$ & $(0.02)$ & $(0.02)$ \\
Democrat & $0.32^{*}$ & $0.38^{*}$ & $0.19^{*}$ & $0.38^{*}$ \\
& $(0.01)$ & $(0.02)$ & $(0.02)$ & $(0.02)$ \\
Incentive Treatment & $0.07^{*}$ & $0.09^{*}$ & 0.00 & $0.11^{*}$ \\
& $(0.02)$ & $(0.02)$ & $(0.02)$ & $(0.02)$ \\
Democrat $\times$ Incentive Treatment & $-0.10^{*}$ & $-0.12^{*}$ & $-0.08^{*}$ & $-0.11^{*}$ \\
& $(0.02)$ & $(0.02)$ & $(0.03)$ & $(0.02)$ \\
\hline$N$ & 11761 & 6197 & 3844 & 7917 \\
\hline Robust standard errors, clustered by respondent, in parentheses & & & \\
Models include item fixed effects & & & & \\
${ }^{*}$ indicates significance at $p<0.05$ & & & & \\
& & & &
\end{tabular}

partisan divide is .22 (95\% Confidence Interval [0.19, 0.24]) among incentivized respondents. Across the other specifications the pattern is similar, roughly 60 to 70 percent of the initial partisan differences persists even when incentives are available.

The persistence of partisan divides in factual beliefs among the groups provided with incentives is noticeably higher than in previous work. In the closest comparison, Bullock et al. $(2015,521)$ find that only $40 \%$ to $45 \%$ of the initial partisan gaps remain when incentives are made available $5^{5}$ This speaks to the more persistent attachment to party-congenial misinformation when survey items address highly polarizing topics, as in our studies. While the treatment effects of incentives across these studies are of similar magnitude to those observed in Bullock et al. (2015), the initial partisan gap on these items is much larger than previously obtained in incentive-based designs.

We also note that, when isolating the information items about unemployment in Appendix Table B.1, we observe a similar pattern of findings to previous work that considers this topic. Our findings diverge from previous studies due to the inclusion of new, more

\footnotetext{
${ }^{5}$ Other studies of misinformation are more difficult to compare as they either focus on correct responses rather than partisan divides (e.g., Prior et al., 2015), or, by design, are only conducted among members of one party (e.g., Berinsky, 2018).
} 
divisive information questions ${ }^{6}$

\section{Incorporating Respondent Certainty About Misinformation}

The preceding analysis may capture a pattern in which partisans choose the incorrect answer when it is party-congenial, but are not particularly confident in their response. For this reason, several studies note the need to consider the certainty with which respondents hold their beliefs (e.g., Pasek et al., 2015; Graham, ND).

To incorporate confidence, we asked respondents how certain they were of their answer on a five-point scale after each information question. We now reassess the partisan divide and the effects of incentives only among those respondents who were certain of their responses to the information questions (i.e., state they are "very" or "extremely" sure of their answer, the top two categories of the five-point certainty scale) and then estimate the effects of incentives on partisan divides in political information.7]

These results are displayed in Table 4, using the same model specification estimated among all partisan respondents (Column 1) and different subsets of the data (Columns 2-4). While the initial magnitude of these partisan divides is smaller across the various specifications in this more stringent coding, the pattern is largely consistent with our earlier analysis. While the availability of incentives reduces partisan gaps on the information items, large divides remain even in the presence of incentives. In the pooled analysis that incorporates

${ }^{6}$ In Appendix B.2 we find no evidence these baseline divides in our study are due to the sample composition and show large divides exist on similar items asked in other surveys.

${ }^{7}$ If incentives affect how certain respondents are of their responses, this specification risks inducing post-treatment bias in our estimates (see e.g., Montgomery et al., 2018). However, we find no direct effect of incentives on response certainty and, in Appendix B.9, observe similar findings when we estimate an alternative specification that incorporates the certainty with which misinformation is held, but is not subject to these concerns. 
Table 4: Effect of Incentives on Partisan Information Divide (Certain Respondents)

\begin{tabular}{lrrrr}
\hline & All Partisans & Strong Partisans & Dem-Valenced & Rep-Valenced \\
\hline (Intercept) & $0.59^{*}$ & $0.52^{*}$ & $0.57^{*}$ & $0.50^{*}$ \\
& $(0.02)$ & $(0.03)$ & $(0.03)$ & $(0.02)$ \\
Democrat & $0.38^{*}$ & $0.46^{*}$ & $0.18^{*}$ & $0.48^{*}$ \\
& $(0.02)$ & $(0.02)$ & $(0.02)$ & $(0.02)$ \\
Incentive Treatment & $0.09^{*}$ & $0.10^{*}$ & -0.02 & $0.15^{*}$ \\
& $(0.02)$ & $(0.03)$ & $(0.02)$ & $(0.03)$ \\
Democrat $\times$ Incentive Treatment & $-0.11^{*}$ & $-0.13^{*}$ & $-0.08^{*}$ & $-0.15^{*}$ \\
& $(0.02)$ & $(0.03)$ & $(0.03)$ & $(0.03)$ \\
\hline$N$ & 8047 & 4477 & 2239 & 5808 \\
\hline Robust standard errors, clustered by respondent, in parentheses & & & \\
Models include item fixed effects & & & & \\
* indicates significance at $p<0.05$ & & & & \\
& & & &
\end{tabular}

all items and partisan respondents, the initial gap between partisans shrinks to roughly twothirds its initial size when respondents receive incentives. This remaining gap of .27 (95\% Confidence Interval $[0.24,0.30])$ is both substantial and statistically significant $\left.\right|^{8}$

In this sense our findings hold even when we account for the possibility that many individuals do not hold their beliefs with a high degree of certainty and are aware they may be wrong (Graham, ND). There are substantial partisan divides over questions of fact that remain in the presence of incentives when we limit the focus to those who are confident in their answers to these questions.

\section{Partisan Divides in News Choice}

We turn next to the impact of incentives on news choice. We group the news sources available to respondents into four categories: a co-partisan news source (e.g., Fox News for Republicans), an out-partisan news source (e.g., Huffington Post for Republicans), the two

${ }^{8}$ Appendix Table B12 also shows partisan divides remain among low-certainty respondents even when incentives are made available. 
mainstream (i.e., non-partisan) news sources and the domain-specific expert source.9

In the control condition lacking incentives, the partisan divide in news choice is glaring. Across the news selections made in the control condition of the surveys (i.e., those where respondents were not assigned incentives for correct answers to the information questions), $29 \%$ of selections went to a co-partisan source, $26 \%$ went to the expert source, $38 \%$ to one of the two mainstream news sources and only $7 \%$ to an out-party source. This 4:1 ratio in the selection of co-partisan sources, relative to out-partisan sources, is far from a complete partisan echo chamber, but indicates that partisans prefer in-party to opposing sources by a wide margin. This is consistent with recent observational studies of online web browsing behavior which find that, with respect to political news, partisans differ in their typical media diet even as they do not completely retreat into echo chambers (see e.g., Peterson et al., ND, Flaxman et al., 2016, Guess, 2019).10

How did the availability of incentives change these baseline patterns of news consumption? The partisan cheerleading hypothesis leads us to expect a decline in reliance on congenial sources in the incentivized condition. Conversely, the motivated reasoning hypothesis predicts that partisans' preferences for biased information will be unaffected by incentives. We distinguish between these accounts by estimating the effects of incentives across the different news choice outcomes using the following specification, in which we regress an indicator variable for news selection on the incentive treatment and a fixed effect for each information item:

$$
\text { News }_{\text {Choice }} \text { }_{k}=\beta_{0}+\beta_{1} \text { Incentive Treatment }_{i}+\beta_{2} \text { Democrat }_{i}+\alpha_{k}+\epsilon_{i k}
$$

\footnotetext{
${ }^{9}$ We observe similar results when using a finer distinction between the different news sources. See Appendix B.

${ }^{10}$ As we later document in greater detail, these divides are also comparable to those that emerge in real-world media choices outside the survey setting.
} 
Table 5 displays the results of these regressions. The first column shows the effects of the incentive treatment on the probability that a respondent selected a co-partisan source (i.e., the outcome is an indicator variable for whether a co-partisan source was selected or not). The second column does this for the expert source. The third column uses a binary indicator for selecting one of the two mainstream news sources as an outcome. Finally, the fourth column does so for the out-partisan source.

Table 5: Effect of Incentives on Information Source Selection

\begin{tabular}{lcccr}
\hline & Co-Partisan News & Expert & Mainstream News & Out-Partisan News \\
\hline (Intercept) & $0.41^{*}$ & $0.37^{*}$ & $0.16^{*}$ & $0.06^{*}$ \\
Incentive Treatment & $(0.02)$ & $(0.02)$ & $(0.02)$ & $(0.01)$ \\
& -0.00 & -0.00 & 0.01 & -0.00 \\
& $(0.01)$ & $(0.01)$ & $(0.01)$ & $(0.01)$ \\
\hline$N$ & 11821 & 11821 & 11821 & 11821 \\
\hline
\end{tabular}

Robust standard errors, clustered by respondent, in parentheses

Models include item fixed effects and condition on respondent partisanship

A similar pattern holds across all these outcomes. Incentives have no effect whatsoever on news choice. For instance, in Column 1 the point estimate for the effect of incentives on the probability of selecting a co-partisan news source is negative, but substantively small and indistinguishable from zero $(-0.003,95 \%$ Confidence Interval $[-0.03,0.02])$. This pattern of no sizeable or statistically significant effects of incentives on information source selection continues when we consider the probability of selecting an expert source (Column 2), one of the two mainstream news sources that was available (Column 3) or an out-partisan news source (Column 4)

In contrast to the evidence of modest partisan cheerleading for the information items, we observe no change in news choices when incentives are made available. The continued use of co-partisan information sources in the incentivized condition suggests that the partisans who use them do not believe the information provided by party-congenial sources is any

\footnotetext{
${ }^{11}$ In Appendix B we show there are similar results when we examine each party separately.
} 
less accurate than information from non-partisan or expert sources. As predicted by the motivated reasoning hypothesis, partisans' news preferences are immune to the effects of financial incentives.

\section{Comparison With Real-World Media Choice}

A fundamental limitation of survey experimental designs is the generalizability of behavior observed in the experimental context (Barabas and Jerit, 2010). For our results, this raises several concerns. First, participants' news preferences, irrespective of the condition to which they were assigned, may have been influenced by "demand" effects - subtle cues conveyed by the study description or instructions - which may influence party-congenial news selection in both the treatment and control groups (but see Mummolo and Peterson, 2019). Second, to the extent partisans know the correct answer to knowledge questions when they enter the survey - and whether or not they ultimately plan to answer these questions in a sincere manner - they may not need to acquire new information over the course of the survey even when incentivized. This means both the unincentivized and incentivized conditions of our surveys could exaggerate partisans' tendency to search for information from party-congenial sources relative to their real-world tendency to do so.

Fortunately, we can draw on the unique nature of our dataset to address concerns that the in-survey news selections made over the course of the experiment do not mirror everyday news consumption. 855 of the respondents in the survey were members of the YouGov Pulse Panel. They had all consented to install a toolbar on their primary desktop web browser that tracked the websites they visited in the months prior to these surveys 22 They received YouGov points for keeping the toolbar active, but had the option to turn it off if they wished.

${ }^{12}$ For recruitment, YouGov employs a consent screen using language taken from the Market Research Society's code of conduct. Panelists are informed that their web browsing behavior will remain anonymous and that the data will only be used for research purposes. 
In general, measures of web traffic collected from this panel resemble those from sources (see e.g., Guess, 2019; Peterson et al. ND for other applications in political science).

For this group of respondents, we can compare the news choices they made within the experiment with their normal web browsing behavior. We emphasize here that our measure only captures web browsing conducted from desktop computers. This misses other forms of media use (e.g., mobile web browsing and cable television consumption). We note our evidence cannot speak to the correspondence between survey-based and behavioral measures of media exposure in these other settings, which represent a setting for future work. In this case we proceed using this measure of desktop-based online news exposure as it provides an important supplement to our previous analysis. This data offers the chance to see whether the news choices respondents make within the survey context align with their behavior in an important form of news consumption outside the survey.

We compare the partisan slant of a respondent's real-world media diet to the partisan slant of the news selections they made in our surveys. We characterize the partisan slant of media choices in the experiment as a trichotomy, with right-leaning sources scored as one, the mainstream and expert sources as zero, and left-leaning sources as negative one ${ }^{13}$ We average this measure across the multiple news choices respondents made over the course of the survey. We then compare this indicator of preference for partisan news with the slant that respondents displayed in their everyday browsing behavior. We characterize the partisanship of their web browsing behavior outside the experimental setting using the "alignment scores"

\footnotetext{
${ }^{13}$ We recognize that, in public perceptions of their perceived slant and the partisanship of their audiences, the mainstream outlets we consider (i.e., CNN and the New York Times) appear similar to the left-leaning news sources (i.e., Huffington Post and MSNBC). In Appendix C.2 we observe similar results using two alternative measures of the partisanship of an individual's survey-based media choices.
} 
for a set of 452 news websites presented in Bakshy et al. (2015) The alignment scores reflect the partisanship of news domains based on the ideology of individuals who shared their content on Facebook. Domains shared more frequently by conservatives receive alignment scores closer to 1 , while those offering content shared more frequently by liberals receive scores closer to -1 .

Figure 1 displays the comparison of a respondent's real-world media slant (the X axis) to the slant of their news selections in the experimental context (the $\mathrm{Y}$ axis). Individual observations are shown in gray. We use a loess smoother to plot the relationship between these variables. The dashed line corresponds to a slope of one, providing a baseline of exact correspondence between the two measures of slant.

Figure 1 shows that news-seeking behavior within the experiment differs only slightly from news consumption in the real world. The correspondence is particularly strong for those with everyday media diets that range from moderate to conservative. For respondents at the other end of the ideological spectrum the correspondence is weaker; those with very liberal real-world media preferences were less apt to rely on the left-leaning sources available in the experiment. Overall, there is a substantial correlation (.58) between the two measures of partisan slant. Relative to other comparisons of attitudes or behaviors observed within survey settings and real-world behavior (see, for instance, Wicker, 1969; Bertrand and Mullainathan, 2001), this represents an impressive degree of correspondence.

Having validated our measure of news preferences (partisan slant), we turn to the question of whether incentives strengthen or weaken the partisan divide in news preferences. For this

\footnotetext{
${ }^{14}$ The original data contain five hundred websites, but for our study we drop non-news sources included in the original data (e.g., Amazon, Wikipedia) and websites no longer in operation over the time window we consider. As in Peterson et al. ND, we also restrict our analysis of several high-traffic websites that contain both news and non-news content (i.e., Yahoo, MSN and AOL) to traffic to the news portions of those websites.
} 
Figure 1: Partisan Slant of Survey and Real-World News Choice

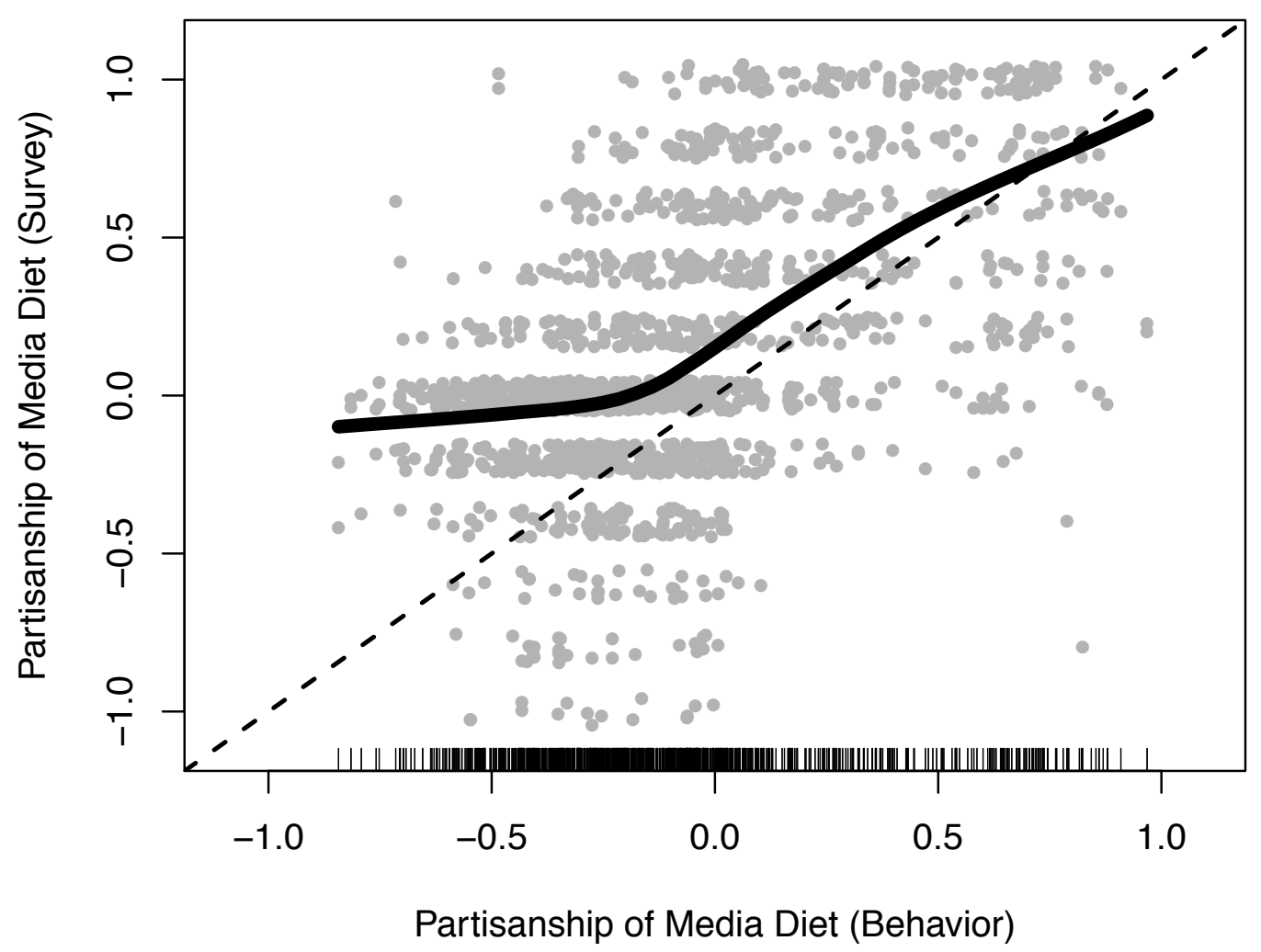

analysis, we calculate the difference between the average media choice for Democrats and the average media choice for Republicans (scaled in terms of the standard deviation of each outcome) for the three relevant settings - the unincentivized survey, the incentivized survey condition, and everyday web browsing behavior. The cheerleading prediction is that the partisan divide in media choice should shrink under incentives and outside of the survey; the motivated reasoning prediction is that the partisan divide will remain stable across all three settings. We present the results in Table 6 . 
Table 6: Partisan Divides in Media Choice By Setting

\begin{tabular}{ll} 
Setting & Partisan Divide \\
\hline Survey + No Incentives & $1.24 \mathrm{SD}$ \\
Survey + Incentives & $1.30 \mathrm{SD}$ \\
Real-World Media Diet & $1.36 \mathrm{SD}$
\end{tabular}

As shown in Table 6, partisan differences in news preferences are of similar magnitude across the different settings. These divides prove durable to the presence of incentives and when examined outside the survey environment. Altogether, we find little evidence that partisans exaggerate their affinity for co-partisan news sources inside surveys relative to the manner in which they typically consume political news outside that context.

\section{Discussion and Conclusion}

The rise of partisan divides over factual evidence in surveys is readily apparent. But does this trend pose a genuine threat to the democratic process? To understand the scope of the problem - and whether potential remedies involve improving measures of beliefs about politics to reduce cheerleading or efforts to correct genuinely held misinformation (see e.g., Jerit and Zhao, ND; Porter and Wood, 2019) - we assessed the relative importance of motivated reasoning and cheerleading as explanations for misinformation.

\section{Implications for Political Misinformation}

We first discuss the implications of the substantial partisan divides over political information. Consistent with the motivated reasoning perspective, our studies indicate that partisans are genuinely committed to the inaccurate beliefs they report in surveys. The threat to democratic functioning posed by polarization is real. The availability of incentives reduced, but did not eliminate, the partisan divide in information. Approximately two-thirds of the 
initial partisan divide in the unincentivized conditions persisted when we offered respondents the opportunity to earn rewards for correct responses. We observed this pattern for both Democrats and Republicans, depending on the partisan valence of the topic.

One challenge to the validity of this motivated reasoning interpretation is that we cannot address the possibility that, for some partisans, the "psychic" rewards for cheerleading exceed the monetary rewards available in our studies. This would mean the incentive conditions in our design still contain some degree of insincere cheerleading. Future research will need to assess the elasticity of survey respondents' responsiveness to even larger incentives than those we employ here (for some evidence that larger amounts exert stronger remedial effects, see Bullock et al., 2015).

Relatedly, there is a need to calibrate incentive levels in these designs to match those individuals face in the real world. Prior studies offer mixed evidence on this point. On the one hand, much political decision-making occurs in a context that more closely resembles an unincentivized survey than one in which clear material benefits for accuracy are available. A long tradition in political science emphasizes that the material benefits of political participation that accrue to individuals are trivial (Downs, 1957) and, absent an express admonition to avoid bias, previous studies find that information processing appears to resemble motivated reasoning (Bolsen et al., 2014; Prior et al., 2015). On the other hand, the material incentives for accuracy available in our study are likely weaker than those facing voters who perceive substantial societal stakes in an election outcome (Edlin et al., 2007) or feel social pressure to accurately process information (Klar, 2014).

Given the ambiguity over the scale of incentives offered in our study versus those that apply naturalistically, we are unable to make claims about the realism of our manipulations. Instead, our primary contribution is to show that partisan divides over a new class of political information items - those directly related to ongoing political controversies - prove more resistant to incentives than the types of information questions previously considered. 


\section{Implications for Political Information Search}

Relative to the findings on misinformation, our evidence concerning information search provides more one-sided support for motivated reasoning. Partisans consulted congenial sources to the same extent whether or not they were incentivized to answer correctly. Moreover, the partisan divides in news choice present in the survey were no different from the divides in the same respondents' everyday news browsing behavior. Here we are better able to address concerns about how the survey environment compares to real-world contexts. The ready translation of partisan divides in the survey into web browsing behavior outside it suggests that, in terms of their ability to motivate information search, incentives for accuracy are no more pronounced in real-world news use than in the unincentivized survey conditions.

\section{Methodological Implications}

Finally, while our primary focus has been directed at the motivated reasoning versus cheerleading debate, this study also yields two methodological lessons. First, the partisan slant of individuals' news preferences, as elicited through a set of information-seeking tasks, corresponds to real-world news consumption. While concerns over inaccurate measures of news exposure are endemic in survey research, particularly when it comes to respondents' ability to recall accurately the amount of news they encounter from various platforms (e.g. Guess, 2015, Prior, 2009), we find that eliciting the partisanship of a respondent's news preferences through a series of information-seeking tasks matches well with the preferences revealed in their everyday behavior.

Second, our modified incentive design also sheds light on the psychological processes underlying the remedial effects of incentives in surveys. Bullock and Lenz (2019) point out that the impact of incentives on accurate survey responses might occur either because respondents expend greater effort when asked an information question or due to increased 
honesty (i.e., incentives discourage individuals who know the correct answer from responding incorrectly). Our study speaks to this distinction by showing that at the information-search stage, the availability of incentives does not alter respondent interest in information from expert sources. On the assumption that comprehension of information provided by expert sources requires greater effort, this lack of movement in information search is consistent with the interpretation that the mechanism underlying the effects of incentives is not cognitive effort, but honesty, as posited in previous studies of partisan cheerleading.

In closing, we note this study raises important questions for future research. We have interpreted the magnitude of the partisan information divide and the stability of partisans' preferences for congenial information as evidence of motivated reasoning stemming from polarization -- the interpretation commonly given in the misinformation literature. However, partisan motives may come into play at different stages of the belief formation process, beginning with information reception and following through to information acceptance (see, for instance, the classic description of these stages in McGuire, 1985). Partisans' continued preference for co-partisan news providers, for instance, suggests that the expression of misinformed beliefs may have less to do with selective interpretation of neutral or unbiased information, and more to do with exposure to one-sided or biased information in the first place. Mapping the effects of partisan motivated reasoning through the stages of belief formation represents a promising agenda for misinformation research. 


\section{References}

Almond, Gabriel. 1950. The American People and Foreign Policy. Harcourt.

Barabas, Jason and Jennifer Jerit. 2010. "Are Survey Experiments Externally Valid?" American Political Science Review 104(2): 226-242.

Bakshy, Eytan, Solomon Messing and Lada Adamic. 2015. "Exposure to Ideologically Diverse News and Opinion on Facebook." Science 348(6239): 1130-1132.

Bartels, Larry M. 2002. "Beyond the Running Tally: Partisan Bias in Political Perceptions." Political Behavior 24(2), 117-150.

Berinsky, Adam. 2018. "Telling the Truth about Believing the Lies? Evidence for the Limited Prevalence of Expressive Survey Responding." Journal of Politics 81(1): 20112024 .

Berinsky, Adam. 2017. "Rumors and Health Care Reform: Experiments in Political Misinformation." British Journal of Political Science 47(2): 241-262.

Bertrand, Marianne and Sendhil Mullainathan. 2001. "Do People Mean What They Say? Implications for Subjective Survey Data." American Economic Review 91(2): 67-72.

Bisgaard, Martin. 2015. "Bias Will Find a Way: Economic Perceptions, Attributions of Blame, and Partisan-Motivated Reasoning During Crisis." Journal of Politics 77(3): 849860.

Bisgaard, Martin and Rune Slothuus. 2018. "Partisan Elites as Culprits? How Party Cues Shape Perceptual Gaps." American Journal of Political Science 62(2): 456-469.

Bolsen, Toby, James N. Druckman and Fay Lomax Cook. 2014. "The Influence of Partisan Motivated Reasoning on Public Opinion." Political Behavior 36(2): 235-262.

Bullock, John and Gabriel Lenz. 2019. "Partisan Bias in Surveys." Annual Review of Political Science 22: 325-342.

Bullock John, Alan Gerber, Seth Hill and Gregory Huber. 2015. "Partisan Bias in Factual 
Beliefs about Politics." Quarterly Journal of Political Science 10, 519-578.

Delli Carpini, Michael and Scott Keeter. 1996. What Americans Know about Politics and Why It Matters. Yale University Press.

Druckman, James N. and Mary C. McGrath. 2019. "The Evidence for Motivated Reasoning in Climate Change Preference Formation." Nature Climate Change 9:111-119.

Druckman, James N., Erik Peterson and Rune Slothuus. 2013. "How Elite Partisan Polarization Affects Public Opinion Formation." American Political Science Review 107(1), $57-79$.

Edlin, Aaron, Andrew Gelman and Noah Kaplan. 2007. "Voting as a Rational Choice: Why and How People Vote to Improve the Well-Being of Others." Rationality and Society 19(3): 293-314.

Enns, Peter K., Paul M. Kellstedt and Gregory E. McAvoy. 2012. "The Political Consequences of Partisanship in Economic Perceptions." Public Opinion Quarterly 76(2), 287-310.

Festinger, Leon. 1957. A Theory of Cognitive Dissonance. Stanford University Press.

Flaxman, Seth, Sharad Goel and Justin M. Rao. 2016. "Filter Bubbles, Echo Chambers and Online News Consumption." Public Opinion Quarterly 80(S1): 298-320.

Flynn, D.J. and Yanna Krupnikov. 2019. "Misinformation and the Justification of Socially Undesirable Preferences." Journal of Experimental Political Science 6(1): 5-16.

Flynn, D.J., Brendan Nyhan and Jason Reifler. 2017. "The Nature and Origins of Misperceptions." Political Psychology 38(S1): 127-150.

Gaines, Brian J., James H. Kuklinski, Paul J. Quirk, Buddy Peyton and Jay Verkuilen. 2007. "Same Facts, Different Interpretations: Partisan Motivation and Opinion on Iraq." Journal of Politics 69(4), 957-974.

Garrett, R. Kelly, Brian E. Weeks and Rachel L. Neo. 2016. "Driving a Wedge Between Evidence and Beliefs: How Online Ideology News Exposure Promotes Misperceptions." 
Journal of Computer-Mediated Communication 21(5): 331-348.

Graham, Matthew H. ND. "Self-Awareness of Political Knowledge." Political Behavior Forthcoming.

Guess, Andrew. 2019. “(Almost) Everything in Moderation: New Evidence on Americans' Online Media Diets." Working Paper. https://www.dropbox.com/s/4qbn2910pkpe2oa/ Guess_OMD.pdf?dl=0 Last Accessed: April 13, 2020.

Guess, Andrew. 2015. "Measure for Measure: An Experimental Test of Online Political Media Exposure." Political Analysis 23: 59-75.

Hochschild, Jennifer and Katherine Einstein. 2015. "Do Facts Matter? Information and Misinformation in American Politics." Political Science Quarterly 130(4): 585-624.

Huber, Gregory A. and Neil Malhotra. 2017. "Political Homophily in Social Relationships: Evidence from Online Dating Behavior." Journal of Politics 79(1): 269-283.

Iyengar, Shanto and Kyu S. Hahn. 2009. "Red Media, Blue Media: Evidence of Ideological Selectivity in Media Use." Journal of Communication 59(1), 19-39.

Iyengar, Shanto, Gaurav Sood and Yphtach Lelkes. 2012. "Affect, Not Ideology: A Social Identity Perspective on Polarization." Public Opinion Quarterly 76(3): 405-431.

Iyengar, Shanto, Tobias Konitzer and Kent Tedin. 2018. "The Home as a Political Fortress: Family Agreement in an Era of Polarization." Journal of Politics 80(4): 1326-1338.

Jerit, Jennifer and Yangzi Zhao. ND. "Political Misinformation." Annual Review of Political Science Forthcoming.

Jerit, Jennifer, and Jason Barabas. 2012. "Partisan Perceptual Bias and the Information Environment." Journal of Politics 74(3): 672-684.

Kim, Jin Woo and Eunji Kim. 2019. "Identifying the Effect of Political Rumor Diffusion Using Variations in Survey Timing." Quarterly Journal of Political Science 14(3): 293311.

Klar, Samara. 2014. "Partisanship in a Social Setting." American Journal of Political 
Science 58(3): 687-704.

Kraft, Patrick W., Milton Lodge and Charles S. Taber. 2015. "Why People 'Don't trust the evidence': Motivated Reasoning and Scientific Beliefs." The ANNALS of the American Academy of Political and Social Science 658(1): 121-133.

Kreisberg, Martin. 1949. "Dark Areas of Ignorance." in Public Opinion and Foreign Policy (Ed. L. Markel). pp 49-64. Harper.

Kunda, Ziva. 1990. "The Case for Motivated Reasoning." Psychological Bulletin 108(3), 480-498.

Kuklinski, James H., Paul J. Quirk, Jennifer Jerit, David Schwieder, and Robert F. Rich. 2000. "Misinformation and the Currency of Democratic Citizenship." Journal of Politics 62(3): $790-816$.

Levendusky, Matthew. 2010. "Clearer Cues, More Consistent Voters: A Benefit of Elite Polarization." Political Behavior 32(1): 111-131.

Lippmann, Walter. 1922. Public Opinion. Harcourt, Brace \& Co.

Lord, Charles G., Lee Ross and Mark R. Lepper. 1979. "Biased Assimilation and Attitude Polarization: The Effects of Prior Theories on Subsequently Considered Evidence." Journal of Personality and Social Psychology 37(11): 2098-2109.

Lodge, Milton and Charles S. Taber. 2013. The Rationalizing Voter. Cambridge University Press.

Mason, Lilliana. 2018. Uncivil Agreement: How Politics Became Our Identity. University of Chicago Press.

McGrath, Mary C. 2017. "Economic Behavior and the Partisan Perceptual Screen." Quarterly Journal of Political Science 11(4): 363-383.

McGuire, William J. 1985. "Attitudes and Attitude Change." in The Handbook of Social Psychology (Eds. G. LIndzey and E. Aronson) Random House. pp 233-346.

Mian, Atif, Amir Sufi and Nasim Khoshkhou. 2017. "Partisan Bias, Econoimc Expec- 
tations, and Household Spending." Working Paper. https://faculty.chicagobooth. edu/amir.sufi/research/papers/miansufikhoshkhou_partisanbias.pdf Last Accessed:

April 13, 2020.

Miller, Joanne M., Kyle L. Saunders and Christina E. Farhart. 2016. "Conspiracy Endorsement as Motivated Reasoning: The Moderating Roles of Political Knowledge and Trust." American Journal of Political Science 60(4): 824-844.

Montgomery, Jacob M., Brendan Nyhan and Michelle Torres. 2018. "How Conditioning on Posttreatment Variables Can Ruin Your Experiment and What To Do About It." American Journal of Political Science 62(3): 760-775.

Mummolo, Jonathan and Erik Peterson. 2019. "Demand Effects in Survey Experiments: An Empirical Assessment." American Political Science Review 113(2): 517-529.

Nyhan, Brendan. 2010. "Why the 'death panel' myth won't die." The Forum 8(1).

Pasek, Josh, Tobias H. Stark, Jon A. Krosnick and Trevor Tompson. 2015. "What Motivates a Conspiracy Theory? Birther Beliefs, Partisanship, Liberal-Conservative Ideology, and anti-Black Attitudes." Electoral Studies 40: 482-489.

Peterson, Erik, Sharad Goel and Shanto Iyengar. ND. "Partisan Selective Exposure in Online News Consumption: Evidence from the 2016 Presidential Campaign." Political Science Research 85 Methods Forthcoming.

Porter, Ethan and Thomas J. Wood. 2019. False Alarm: The Truth about Political Mistruths in the Trump Era. Cambridge University Press.

Prior, Markus. 2013. "Media and Political Polarization." Annual Review of Political Science 16: 101-127.

Prior, Markus. 2009. "Improving Media Effects Research through Better Measurement of News Exposure" Journal of Politics 71(3): 893-908.

Prior, Markus and Arthur Lupia. 2008. "Money, Time, and Political Knowledge: Distinguishing Quick Recall and Political Learning Skills." American Journal of Political 
Science 52(1), 169-183.

Prior, Markus, Gaurav Sood, and Kabir Khanna. 2015. "You Cannot be Serious: The Impact of Accuracy Incentives on Partisan Bias in Reports of Economic Perceptions." Quarterly Journal of Political Science 10(4): 489-518.

Roush, Carolyn and Gaurav Sood. 2019. "A Gap in Our Understanding? Reconsidering the Evidence for Partisan Knowledge Gaps." Working Paper. https://www.gsood.com/ research/papers/partisan_gap.pdf Last Accessed: April 13, 2020.

Schaffner, Brian F. and Samantha Luks. 2018. "Misinformation or Expressive Responding? What an inauguration crowd can tell us about the source of political misinformation in surveys." Public Opinion Quarterly 82(1): 135-147.

Schaffner, Brian F. and Cameron Roche. 2017. "Misinformation and Motivated Reasoning: Responses to Economic News in a Politicized Environment." Public Opinion Quarterly 81(1): 86-110.

Shapiro, Robert and and Yaeli Bloch-Elkon. 2008. "Do The Facts Speak For Themselves? Partisan Disagreement as a Challenge to Democratic Competence." Critical Review 20(12): 115-139.

Stroud, Natalie Jomini. 2011. Niche News. Oxford University Press.

Swire, Briony, Adam J. Berinsky, Stephan Lewandowsky and Ullrich Ecker. 2017. "Processing Political Misinformation: Comprehending the Trump Phenomenon." Royal Society Open Science 4(3): 160802.

Thorson, Emily. 2016. "Belief Echoes: The Persistent Effects of Corrected Misinformation." Political Communication 33(3): 460-480.

Vavreck, Lynn and Shanto Iyengar. 2011. "The Future of Political Communication Research: Online Panels and Experimentation." in Oxford Handbook of American Public Opinion and Media (Eds. George C. Edwards III, Robert Shapiro and Lawrence Jacobs.)

Wicker, Allan W. 1969. "Attitudes Versus Actions: The Relationship of Verbal and Overt 
Behavioral Responses to Attitude Objects." Journal of Social Issues 25(4): 41-78. 
Supporting Information for:

"Partisan Gaps in Political Information and Information-Seeking Behavior: Motivated Reasoning or Cheerleading?" 


\section{Contents}

\begin{tabular}{|ll}
\hline A Appendix A: Survey Information & 1
\end{tabular}

A.1 Survey Sample Descriptives . . . . . . . . . . . . . . . . . . 1

A.2 Information Sources by Topic . . . . . . . . . . . . . . . . . . 2

A.3 Format of News Choice Tasks . . . . . . . . . . . . . . . . . . . . . . 3

\begin{tabular}{|lll}
\hline B Appendix B: Supplemental Experimental Analyses & 4
\end{tabular}

B.1 Partisan Differences by Item and Incentive Condition . . . . . . . . . . . . . 4

B.2 Partisan Differences in Unincentivized Conditions . . . . . . . . . . . . . . 6

B.3 Effects of Incentives Using Sampling Weights . . . . . . . . . . . . . . . . . . 7

B.4 Responsiveness of Independents to Incentives . . . . . . . . . . . . . . . . . . 8

B.5 Effects of Incentives on News Choice . . . . . . . . . . . . . . . . . . . . . . 9

B.6 Distribution of Response Certainty by Item . . . . . . . . . . . . . . . . . . 11

B.7 Incorporating Response Certainty . . . . . . . . . . . . . . . . . . . . . . 12

B.8 Effect of Incentives Among Low-Certainty Respondents . . . . . . . . . . . . 12

B.9 Isolating Confidently Held Misinformation . . . . . . . . . . . . . . . . . 13

B.10 Incorporating Response Direction and Certainty . . . . . . . . . . . . . . . . 14

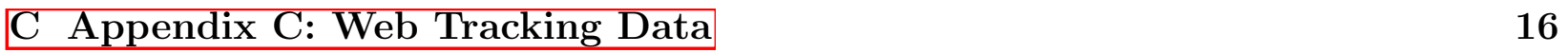

C.1 Web Traffic Sample Descriptives . . . . . . . . . . . . . . . . . . . . . 16

C.2 Alternative Coding of Survey-Based News Choice . . . . . . . . . . . . . . . 17

C.3 Explaining Survey-Based News Choice . . . . . . . . . . . . . . . . . . . . . 20 


\section{A Appendix A: Survey Information}

\section{A.1 Survey Sample Descriptives}

Respondents were recruited using YouGov's standard approach of matching a non-representative online sample to a nationally representative target. This has been utilized in a variety of public opinion studies, including the Cooperative Congressional Election Study.

The table below displays the unweighted demographic composition of the pooled sample (unweighted, as in the main text), survey 1 sample (weighted) and the survey 2 sample (weighted). Because there was a panel structure to the survey data, in which 954 respon-

dents were re-interviewed and appeared in both, the total number of unique respondents is less than the sum of respondents across the two survey waves. As we present the pooled, unweighted results in the main text we do not incorporate them in this analysis either, although we note our results remain similar when we reanalyze the experiments in each survey individually using the sampling weights provided by YouGov (See Appendix B) 
Table A1: Sample Demographics

\begin{tabular}{rllll}
\hline Study & $\begin{array}{l}\text { CCES } \\
\text { (Weighted) }\end{array}$ & $\begin{array}{l}\text { Pooled } \\
\text { (Unweighted) }\end{array}$ & $\begin{array}{l}\text { Survey 1 } \\
\text { (Weighted) }\end{array}$ & $\begin{array}{l}\text { Survey 2 } \\
\text { (Weighted) }\end{array}$ \\
\hline Black & 0.12 & 0.07 & 0.11 & 0.12 \\
Hispanic & 0.07 & 0.07 & 0.09 & 0.15 \\
White & 0.73 & 0.79 & 0.73 & 0.65 \\
Other Race & 0.07 & 0.08 & 0.07 & 0.08 \\
College Plus & 0.26 & 0.39 & 0.38 & 0.30 \\
Female & 0.52 & 0.53 & 0.54 & 0.52 \\
Age & 47.1 & 54.38 & 49.84 & 47.45 \\
Income (\$) & 64581.65 & 71430.70 & 69622.90 & 65729.42 \\
Democrat & 0.46 & 0.49 & 0.51 & 0.49 \\
Republican & 0.36 & 0.37 & 0.35 & 0.37 \\
Independent & 0.18 & 0.14 & 0.14 & 0.14 \\
\hline Sample Size & 64600 & 1852 & 1017 & 1754 \\
\hline
\end{tabular}

As a point of reference for the survey demographics, we also display the same information for the 2016 CCES. The unweighted sample composition analyzed in our study is generally more educated and more white than the CCES sample.

\section{A.2 Information Sources by Topic}

The table below contains the information sources that were available prior to each information question. Subjects saw the source name and headline for each articles as they made a selection of which article to read. For information items included in both the first and second surveys, the same sources/articles were available in each.

Table A2: News Sources by Topic

\begin{tabular}{l|l|l|l|l|l}
\hline & Left Partisan & Mainstream 1 & Mainstream 2 & Expert & Right Partisan \\
\hline Climate Change & HuffPo & CNN & NY Times & National Academy of Science & Breitbart \\
\hline Cohen Plea & HuffPo & CNN & NY Times & New York Law Journal & Breitbart \\
\hline Firearm Sales & HuffPo & CNN & NY Times & American Academy of Pediatrics & Fox \\
\hline Immigrant Crime & HuffPo & CNN & NY Times & National Academy of Science & Breitbart \\
\hline Obama Wiretap & HuffPo & CNN & NY Times & Department of Justice & Fox \\
\hline Voter Fraud & HuffPo & CNN & NY Times & White House Press Office & Fox \\
\hline Unemployment & MSNBC & CNN & NY Times & Bureau of Labor Statistics & Fox \\
\hline
\end{tabular}




\section{A.3 Format of News Choice Tasks}

When making each news selection, respondents saw a list of news sources and a headline for each article. The figure below provides an example of the articles available for the voter fraud news selection task.

Figure A1: News Choice Task on Voter Fraud Topic

\section{YouGov}

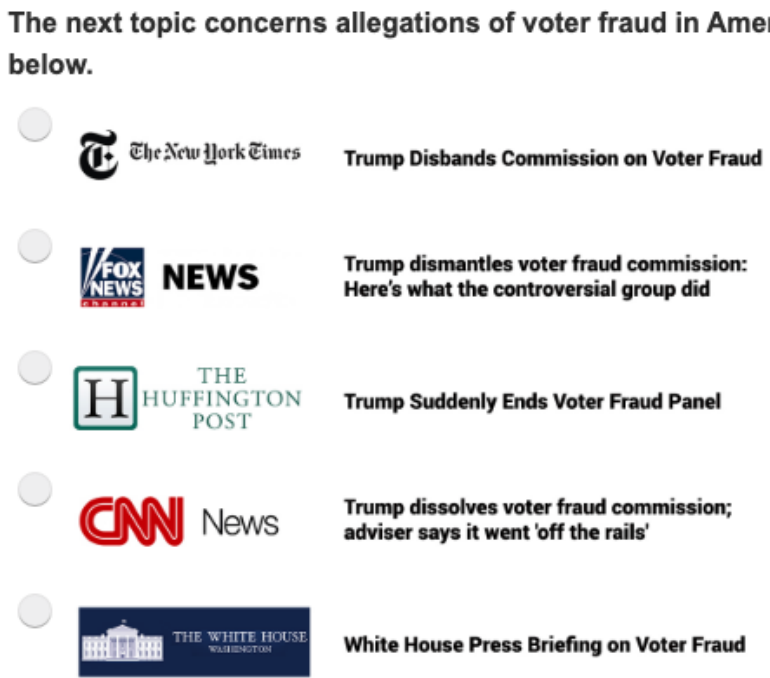

These articles were all based on content that had originally appeared from the source it was attributed to in the survey. This was done to ensure each article could be realistically viewed as coming from that outlet and to ensure the choice set in the study reflected the real-world array of news coverage available on that topic from media outlets with differing ideological reputations. The articles that respondents encountered in the survey were edited to ensure they were of similar length (roughly 250-300 words) for each information source. 


\section{B Appendix B: Supplemental Experimental Analyses}

\section{B.1 Partisan Differences by Item and Incentive Condition}

Table B1 displays the share correctly answering each item among Democrats and Republicans by treatment condition (Unincentivized or Incentivized). This table also displays the baseline difference between Democrats and Republicans in the unincentivized conditions, the between-party difference in the incentivized condition and the difference in party differences between the two conditions.

We note that when we isolate the unemployment items, our findings resemble earlier studies. Here modest initial between-party differences are substantially reduced by the availability of incentives. In contrast, our findings depart from previous work when focusing on the new items introduced into our surveys, where substantial divides remain even when incentives are available. This points to these new survey items, rather than differences in how respondents in these surveys respond to incentives, as the factor that distinguishes the present study from earlier research using the incentive design. 
Table B1: Partisan Differences by Item and Incentive Condition

\begin{tabular}{|c|c|c|c|c|c|c|c|c|}
\hline & Topic & $\begin{array}{l}\text { Dem Correct } \\
\text { (No Incentive) }\end{array}$ & $\begin{array}{r}\text { Rep Correct } \\
\text { (No Incentive) }\end{array}$ & $\begin{array}{r}\text { Baseline } \\
\text { Difference }\end{array}$ & $\begin{array}{r}\text { Dem Correct } \\
\text { (Incentive) }\end{array}$ & $\begin{array}{r}\text { Rep Correct } \\
\text { (Incentive) }\end{array}$ & $\begin{array}{l}\text { Incentive } \\
\text { Difference }\end{array}$ & $\begin{array}{r}\text { Difference } \\
\text { in Difference }\end{array}$ \\
\hline 1 & Climate Change (Survey 1) & 0.96 & 0.63 & 0.33 & 0.95 & 0.69 & 0.26 & 0.07 \\
\hline 2 & Cohen Plea (Survey 2) & 0.93 & 0.80 & 0.13 & 0.89 & 0.80 & 0.09 & 0.04 \\
\hline 3 & Firearm Sales (Survey 2) & 0.22 & 0.56 & -0.34 & 0.24 & 0.49 & -0.25 & -0.09 \\
\hline 4 & Immigrant Crime (Survey 1) & 0.97 & 0.45 & 0.52 & 0.96 & 0.59 & 0.37 & 0.15 \\
\hline 5 & Obama Wiretap (Survey 1) & 0.98 & 0.58 & 0.40 & 0.98 & 0.75 & 0.23 & 0.17 \\
\hline 6 & Obama Wiretap (Survey 2) & 0.98 & 0.53 & 0.45 & 0.97 & 0.73 & 0.24 & 0.21 \\
\hline 8 & Unemployment (Survey 2) & 0.72 & 0.80 & -0.08 & 0.84 & 0.85 & -0.01 & -0.07 \\
\hline 9 & Voter Fraud (Survey 1) & 0.92 & 0.49 & 0.43 & 0.94 & 0.55 & 0.39 & 0.04 \\
\hline 10 & Voter Fraud (Survey 2) & 0.86 & 0.38 & 0.48 & 0.88 & 0.53 & 0.35 & 0.13 \\
\hline
\end{tabular}




\section{B.2 Partisan Differences in Unincentivized Conditions}

Our finding that partisan gaps remain even when incentives for correct answers are available depends, in part, on the substantial divides in the unincentivized conditions. Here we assess whether these baseline gaps are inflated by unrepresentative aspects of our sample.

In Table B2 we consider the magnitude of the partisan divides in the unincentivized conditions of our survey when we incorporate the sampling weights provided by YouGov. For survey 1 we use post-stratification weights for the control group of the study (we received overall weights as well as separate weights for those in the incentived and unincentivized conditions from YouGov). For survey 2 we use the weights designed for the entire sample, but only apply them to the control group.

Table B2: Partisan Differences in Unincentivized Survey Conditions

\begin{tabular}{rlrr}
\hline & Topic & Unweighted & Weighted \\
\hline 1 & Immigrant Crime (Survey 1) & 0.52 & 0.51 \\
2 & Voter Fraud (Survey 2) & 0.48 & 0.39 \\
3 & Obama Wiretap (Survey 2) & 0.45 & 0.44 \\
4 & Voter Fraud (Survey 1) & 0.43 & 0.42 \\
5 & Obama Wiretap (Survey 1) & 0.40 & 0.40 \\
6 & Firearm Sales (Survey 2) & 0.34 & 0.34 \\
7 & Climate Change (Survey 1) & 0.33 & 0.29 \\
8 & Cohen Plea (Survey 2) & 0.13 & 0.12 \\
9 & Unemployment (Survey 1) & 0.11 & 0.16 \\
10 & Unemployment (Survey 2) & 0.08 & 0.12 \\
\hline
\end{tabular}

In both surveys there are limited differences in the partisan divide in the unincentivized conditions when incorporating these weights. This suggests demographics do not inflate the baseline levels of partisan division in our experiments.

Substantial partisan gaps also exist when similar items are asked in other surveys. The 2018 ANES pilot asked respondents "Does illegal immigration increase, decrease or have no effect 
on the crime rate?" $89 \%$ of Republicans indicated they believed illegal immigration increased crime, compared to only $30 \%$ of Democrats. The ANES pilot also asked respondents whether the world's temperature had increased over the past 100 years. 93\% of Democrats indicated this "has probably been happening." Only $56 \%$ of Republicans did. Thus, the partisan gaps revealed in the unincentivized conditions of our surveys are not outliers.

\section{B.3 Effects of Incentives Using Sampling Weights}

Table B3 examines the effects of incentives on partisan divides in political information in each survey individually, rather than the pooled analysis discussed in the main text. For this analysis, we also incorporate sampling weights provided by YouGov that correct for any imbalances between our realized sample and the initial demographic targets.

This analysis shows a largely similar pattern of findings across the two surveys as we find in our pooled analysis in the main text. The initial partisan divide over these items is slightly smaller in the second survey relative to the first. In both cases, the magnitude of the effect of incentives on reducing the initial partisan divide over misinformation is similar. 
Table B3: Effect of Incentives on Partisan Divides over Factual Evidence (By Survey)

\begin{tabular}{lrr}
\hline & Survey 1 & Survey 2 \\
\hline (Intercept) & $0.64^{*}$ & $0.70^{*}$ \\
& $(0.03)$ & $(0.02)$ \\
Democrat & $0.34^{*}$ & $0.28^{*}$ \\
& $(0.03)$ & $(0.02)$ \\
Incentive Treatment & $0.09^{*}$ & $0.07^{*}$ \\
& $(0.03)$ & $(0.02)$ \\
Democrat $\times$ Incentive Treatment & $-0.12^{*}$ & $-0.12^{*}$ \\
& $(0.04)$ & $(0.03)$ \\
\hline$N$ & 4245 & 7516 \\
\hline Robust standard errors, clustered by respondent, in parentheses \\
Models include item fixed effects and incorporate sampling weights \\
$*$ indicates significance at $p<0.05$
\end{tabular}

\section{B.4 Responsiveness of Independents to Incentives}

Our analysis in the main text does not consider "pure" independents who do not lean toward either political party. This is because we lack expectations about the directional factors that will influence them to respond with misinformation on any given item. Table B4 displays the share of independents offering correct answers to each item. The share of independents answering correctly falls in between those answering correctly among Democrats and Republicans. This pattern is expected, as independents lack the directional pressures, either to engage in motivated reasoning or cheerlead for their party, that face partisan respondents across the set of items focused on here. 
Table B4: Correct Answers Among Political Independents

\begin{tabular}{rlr}
\hline & Topic & Share Correct (Independents) \\
\hline 1 & Climate Change (Survey 1) & 0.81 \\
2 & Cohen Plea (Survey 2) & 0.87 \\
3 & Firearm Sales (Survey 2) & 0.36 \\
4 & Immigrant Crime (Survey 1) & 0.72 \\
5 & Obama Wiretap (Survey 1) & 0.78 \\
6 & Obama Wiretap (Survey 2) & 0.78 \\
7 & Unemployment (Survey 1) & 0.79 \\
8 & Unemployment (Survey 2) & 0.76 \\
9 & Voter Fraud (Survey 1) & 0.63 \\
10 & Voter Fraud (Survey 2) & 0.62 \\
\hline
\end{tabular}

Table B5 shows the effect of incentives on correct answers to the information questions among Democrats, Independents and Republicans. When the outcome variable is operationalized in this way, the point estimate for this group falls in between those for Democrats and Republicans, although it does not reach statistical significance.

Table B5: Effect of Incentives on Correct Answers

\begin{tabular}{lrrr}
\hline & Democrats & Independents & Republicans \\
\hline (Intercept) & $0.95^{*}$ & $0.79^{*}$ & $0.62^{*}$ \\
& $(0.01)$ & $(0.04)$ & $(0.03)$ \\
Incentive Treatment & $0.02^{*}$ & 0.04 & $0.07^{*}$ \\
& $(0.01)$ & $(0.02)$ & $(0.01)$ \\
\hline$N$ & 6767 & 1917 & 4994 \\
\hline Robust standard errors in parentheses & & \\
Models include item fixed effects & & \\
$*$ indicates significance at $p<0.05$ & &
\end{tabular}

\section{B.5 Effects of Incentives on News Choice}

We also consider the effects of incentives on news choice among several different sub-groups of the sample. Table B6 examines the effects of incentives on the outcomes we consider in the main text, but only among Democrats. 
Table B6: Effect of Incentives on Information Source Selection (Democrats Only)

\begin{tabular}{lrrrrr}
\hline & Co-Partisan News & Expert & Mainstream News & Out-Partisan News \\
\hline (Intercept) & $0.13^{*}$ & $0.46^{*}$ & $0.36^{*}$ & $0.05^{*}$ \\
& $(0.02)$ & $(0.02)$ & $(0.02)$ & $(0.01)$ \\
Incentive Treatment & -0.02 & -0.00 & 0.02 & 0.00 \\
& $(0.01)$ & $(0.02)$ & $(0.02)$ & $(0.01)$ \\
\hline$N$ & 6807 & 6807 & 6807 & 6807 \\
\hline \multicolumn{2}{l}{ Robust standard errors, clustered by Respondent, in parentheses } & &
\end{tabular}

Table B7 replicates this analysis for Republicans, again finding no substantively significant effect of incentives on news choice.

Table B7: Effect of Incentives on Information Source Selection (Republicans Only)

\begin{tabular}{lcccc}
\hline & Co-Partisan News & Expert & Mainstream News & Out-Partisan News \\
\hline (Intercept) & $0.36^{*}$ & $0.29^{*}$ & $0.28^{*}$ & $0.07^{*}$ \\
& $(0.03)$ & $(0.03)$ & $(0.03)$ & $(0.01)$ \\
Incentive Treatment & 0.02 & -0.00 & -0.01 & -0.00 \\
& $(0.02)$ & $(0.02)$ & $(0.02)$ & $(0.01)$ \\
\hline$N$ & 5014 & 5014 & 5014 & 5014 \\
\hline \multicolumn{2}{l}{ Robust standard errors, clustered by Respondent, in parentheses } & &
\end{tabular}

Table B8 examines the effects, limiting the data to the first study and employing the sampling weights provided by YouGov. It is important to note that in this subset of the data and approach to analysis we observe a decline in co-partisan news choice selection and an increase in the probability of selecting neutral news sources. This appears to be, in part, because including the sampling weights increases the amount of co-partisan source selection in the control group. We note this result does not hold in any of the other pooled or subset analyses we consider (or if we estimate the effects of these features in Study 1 without including sampling weights) and that, even granting a reduction in partisan selective exposure due to incentives, we still observe elevated levels of selectivity even in the conditions where incentives are available, a similar pattern of results to what we see with the information items. 
Table B8: Effect of Incentives on Information Source Selection (Survey 1 Only)

\begin{tabular}{lrrrr}
\hline & Co-Partisan News & Expert & Mainstream News & Out-Partisan News \\
\hline (Intercept) & $0.41^{*}$ & $0.33^{*}$ & $0.18^{*}$ & $0.08^{*}$ \\
Incentive Treatment & $(0.03)$ & $(0.03)$ & $(0.03)$ & $(0.02)$ \\
& $-0.06^{*}$ & $0.06^{*}$ & -0.00 & 0.00 \\
& $(0.03)$ & $(0.03)$ & $(0.03)$ & $(0.01)$ \\
\hline$N$ & 4336 & 4336 & 4336 & 4336 \\
\hline Robust standard errors, clustered by Respondent, in parentheses
\end{tabular}

Table B9 examines the effects of incentives, this time using only the second study and incorporating sampling weights. Here, as with the pooled analysis, we do not observe a significant or substantively large effect of incentives on news selection.

Table B9: Effect of Incentives on Information Source Selection (Survey 2 Only)

\begin{tabular}{lcccc}
\hline & Co-Partisan News & Expert & Mainstream News & Out-Partisan News \\
\hline (Intercept) & $0.38^{*}$ & $0.17^{*}$ & $0.37^{*}$ & $0.09^{*}$ \\
& $(0.02)$ & $(0.02)$ & $(0.03)$ & $(0.01)$ \\
Incentive Treatment & 0.02 & -0.02 & -0.01 & 0.01 \\
& $(0.02)$ & $(0.02)$ & $(0.02)$ & $(0.01)$ \\
\hline$N$ & 7485 & 7485 & 7485 & 7485 \\
\hline Robust standard errors, clustered by Respondent, in parentheses & &
\end{tabular}

Robust standard errors, clustered by Respondent, in parentheses

\section{B.6 Distribution of Response Certainty by Item}

We incorporate measures of response certainty into some of our analyses. Table B8 displays the share of respondents who are "very" or "extremely" certain of their answer across the different items. In general, respondents expressed a relatively high degree of certainty in their answers to the information questions. We suspect this is due to the highly partisan nature of these questions. 
Table B10: Response Certainty by Item

\begin{tabular}{rlr}
\hline & Topic & Share Certain \\
\hline 1 & Immigrant Crime (Survey 1) & 0.81 \\
2 & Climate Change (Survey 1) & 0.78 \\
3 & Voter Fraud (Survey 1) & 0.77 \\
4 & Unemployment (Survey 1) & 0.75 \\
5 & Obama Wiretap (Survey 1) & 0.73 \\
6 & Obama Wiretap (Survey 2) & 0.71 \\
7 & Unemployment (Survey 1) & 0.68 \\
8 & Unemployment (Survey 2) & 0.67 \\
9 & Cohen Plea (Survey 2) & 0.62 \\
10 & Firearm Sales (Survey 2) & 0.38 \\
\hline
\end{tabular}

\section{B.7 Incorporating Response Certainty}

Our analysis that subsets to only those respondents who are "certain" of their answer in the main text is potentially subject to post-treatment bias if the incentive treatments affect both the direction and certainty of responses to the political information questions. Below we consider the effects of incentives on response certainty and do not observe a detectable effects of incentives on this measure.

Table B11: Effect of Incentives on Response Certainty

\begin{tabular}{lc}
\hline & All Partisans \\
\hline (Intercept) & $0.70^{*}$ \\
& $(0.02)$ \\
Incentive Treatment & 0.02 \\
& $(0.01)$ \\
\hline$N$ & 11761 \\
\hline Robust standard errors in parentheses \\
$*$ indicates significance at $p<0.05$
\end{tabular}

\section{B.8 Effect of Incentives Among Low-Certainty Respondents}

To complement the analysis in the main text, here we consider the effects of incentives among respondents that expressed a low level of certainty in their response to the information ques- 
tions. This is a companion table to the one that features high-certainty respondents in the main text (Table 4).

Table B12: Effect of Incentives on Partisan Information Divide (Uncertain Respondents)

\begin{tabular}{lrrrr}
\hline & All Partisans & Strong Partisans & Dem-Valenced & Rep-Valenced \\
\hline (Intercept) & $0.72^{*}$ & $0.71^{*}$ & $0.56^{*}$ & $0.71^{*}$ \\
& $(0.03)$ & $(0.05)$ & $(0.03)$ & $(0.04)$ \\
Democrat & $0.16^{*}$ & $0.19^{*}$ & $0.16^{*}$ & $0.15^{*}$ \\
& $(0.02)$ & $(0.03)$ & $(0.03)$ & $(0.03)$ \\
Incentive Treatment & $0.06^{*}$ & $0.07^{*}$ & 0.03 & $0.08^{*}$ \\
& $(0.02)$ & $(0.03)$ & $(0.04)$ & $(0.03)$ \\
Democrat $\times$ Incentive Treatment & $-0.09^{*}$ & $-0.10^{*}$ & -0.07 & $-0.10^{*}$ \\
& $(0.03)$ & $(0.04)$ & $(0.05)$ & $(0.04)$ \\
\hline$N$ & 3707 & 1715 & 1604 & 2103 \\
\hline Robust standard errors in parentheses & & & & \\
${ }^{*}$ indicates significance at $p<0.05$ & & & &
\end{tabular}

In the conditions in which incentives are available, a partisan divide of 0.07 (95\% Confidence Interval $[.02,11])$ remains. This is roughly $45 \%$ of the initial partisan gap among this group of low-certainty respondents.

\section{B.9 Isolating Confidently Held Misinformation}

Below we estimate a different model specification below to address the question of how large the partisan divides are among those who hold misinformed views in a relatively certain manner. In this specification we reassess the partisan divide using the same approach to constructing our outcome measure as in the main text (i.e., the congenial answer for Democrats always received a higher value), but with a more stringent classification of the "misinformed." For this analysis we define misinformation as the combination of an incorrect response and a high degree of certainty in their response (i.e., partisans who state they are "very" or "extremely" sure of their answer, the top two categories on the five-point certainty scale). If respondents did not meet this category, they were categorized as correct on an issue. This modified outcome measure considers the divide between those who are strongly 
misinformed and the all other respondents.

Table B13: Effect of Incentives on Partisan Information Divide (Isolating Confident and Misinformed Responses)

\begin{tabular}{lrrrr}
\hline & All Partisans & Strong Partisans & Dem-Valenced & Rep-Valenced \\
\hline (Intercept) & $0.76^{*}$ & $0.72^{*}$ & $0.21^{*}$ & $0.72^{*}$ \\
& $(0.02)$ & $(0.02)$ & $(0.01)$ & $(0.02)$ \\
Democrat & $0.19^{*}$ & $0.24^{*}$ & $0.08^{*}$ & $0.25^{*}$ \\
& $(0.01)$ & $(0.02)$ & $(0.02)$ & $(0.02)$ \\
Incentive Treatment & $0.04^{*}$ & $0.05^{*}$ & 0.00 & $0.07^{*}$ \\
& $(0.01)$ & $(0.02)$ & $(0.02)$ & $(0.02)$ \\
Democrat $\times$ Incentive Treatment & $-0.06^{*}$ & $-0.07^{*}$ & $-0.05^{*}$ & $-0.07^{*}$ \\
& $(0.01)$ & $(0.02)$ & $(0.02)$ & $(0.02)$ \\
\hline$N$ & 11761 & 6197 & 3844 & 7917 \\
\hline
\end{tabular}

Robust standard errors, clustered by respondent, in parentheses

Models include item fixed effects

* indicates significance at $p<0.05$

These results are displayed in Table B13, using the same model specification estimated among all partisan respondents (Column 1) and different subsets of the data (Columns 2-4). While the initial magnitude of these partisan divides is smaller across the various specifications in this more stringent coding, the pattern is largely consistent with our earlier analysis. While the availability of incentives reduces partisan gaps on the information items, the divides remain in the presence of incentives. In the pooled analysis that incorporates all items and partisan respondents, the initial gap between partisans shrinks to roughly two-thirds its initial size when respondents receive incentives. This remaining gap of .13 (95\% Confidence Interval $[0.11,0.15])$ is both substantial and statistically significant.

\section{B.10 Incorporating Response Direction and Certainty}

We also consider these divides using a more granular outcome that incorporates both the direction and certainty with which an individual holds their beliefs. More specifically, we create a 10-pt scale by coding responses from 1 (a confidently-held incorrect response) to 10 
(a confidently-held correct response) with the intermediate categories representing more or less confident responses. We then estimate the same set of models included in the main text with this alternative outcome.

Table B14: Effect of Incentives on Partisan Information Divide (10-pt DV Incorporating Certainty)

\begin{tabular}{|c|c|c|c|c|}
\hline & All Partisans & Strong Partisans & Dem-Valenced & Rep-Valenced \\
\hline \multirow[t]{2}{*}{ (Intercept) } & $6.41^{*}$ & $6.06^{*}$ & $5.71^{*}$ & $5.87^{*}$ \\
\hline & $(0.12)$ & $(0.16)$ & $(0.12)$ & $(0.14)$ \\
\hline \multirow[t]{2}{*}{ Partisanship } & $2.78^{*}$ & $3.36^{*}$ & $1.33^{*}$ & $3.50^{*}$ \\
\hline & $(0.09)$ & $(0.12)$ & $(0.14)$ & $(0.11)$ \\
\hline \multirow[t]{2}{*}{ Incentive Treatment } & $0.56^{*}$ & $0.65^{*}$ & -0.04 & $0.86^{*}$ \\
\hline & $(0.11)$ & $(0.16)$ & $(0.15)$ & $(0.14)$ \\
\hline \multirow{2}{*}{ Partisanship $\times$ Incentive Treatment } & $-0.75^{*}$ & $-0.89^{*}$ & $-0.54^{*}$ & $-0.87^{*}$ \\
\hline & $(0.12)$ & $(0.17)$ & $(0.19)$ & $(0.16)$ \\
\hline$N$ & 11754 & 6192 & 3843 & 7911 \\
\hline
\end{tabular}

Using this alternative outcome, we observe a similar pattern to the findings reported in the main text. The initial partisan gap in the unincentivized survey conditions is reduced by $27 \%$ of its initial size when incentives are made available. A partisan gap of 2.03 points (95\% Confidence Interval $[1.86,2.20])$ on this 10 -pt outcome measure remains in the conditions where incentives are made available. 


\section{Appendix C: Web Tracking Data}

\section{C.1 Web Traffic Sample Descriptives}

We observe web tracking data for $46 \%$ of our pooled sample across the two surveys. These survey respondents had all previously agreed to install an online toolbar, from Wakoopa, on their primary desktop web browser. When active, this toolbar tracked the individual urls they encountered while browsing the internet. Respondents were able to turn the toolbar on and off as they wished, but received incentives for keeping it active. We use counts of the number of times they visited 452 news websites that were assigned an alignment score by Bakshy et al. (2015) and average the visit-weighted alignment score of all of a respondent's web traffic in the months preceding the survey (the window of time we observe their web traffic varies by participant based on how long they remained active in using the Wakoopa toolbar) to characterize their news choices outside of the survey context.

Table C1 compares the demographics of our overall sample to only those respondents where we observe web traffic. Because we focus on a within-subject comparison of news choices inside the surveys with web browsing behavior outside the surveys, we do not weight these results. 
Table C1: Comparing Pooled Survey Sample and Web Traffic Sample

\begin{tabular}{rll}
\hline Study & $\begin{array}{l}\text { Pooled } \\
\text { (Unweighted) }\end{array}$ & $\begin{array}{l}\text { Web Traffic } \\
\text { (Unweighted) }\end{array}$ \\
\hline Black & 0.07 & 0.06 \\
Hispanic & 0.07 & 0.05 \\
White & 0.79 & 0.82 \\
Other Race & 0.08 & 0.07 \\
College Plus & 0.39 & 0.43 \\
Female & 0.53 & 0.50 \\
Age & 54.38 & 58.53 \\
Income (\$) & 71430.70 & 71211.93 \\
Democrat & 0.49 & 0.51 \\
Republican & 0.37 & 0.37 \\
Independent & 0.14 & 0.13 \\
\hline Sample Size & 1852 & 855 \\
\hline
\end{tabular}

This comparison shows that those respondents for which we observe web traffic are largely similar to the demographic compositon of our overall pooled sample across the surveys.

\section{C.2 Alternative Coding of Survey-Based News Choice}

In the comparison between survey-based and real-world news choice presented in the main text, we consider visits to CNN and the New York Times to be neutral, from the perspective of partisans, by giving them a similar code to the expert sources. This assumption can be contested in contemporary politics where the partisanship of the audience that these websites receive is not dissimilar from more clearly partisan sources of information such as the Huffington Post.

For this reason, we now consider two alternative approaches to characterizing the partisanship of a respondent's news choices in the surveys. Under Alternative 1, we consider visits to the left-leaning partisan source OR the mainstream news sources to be the same $(-1)$, code visits to the expert source as neutral (0), and visits to the right-leaning source the 
same as in the analysis in the main text (1). The key distinction between this and the findings in the main text is that CNN and the New York Times are now characterized as left-leaning sources. Under Alternative 2, we rely on the same alignment scores from Bakshy et al. (2015) that we used to characterize online news domains to measure the partisanship of survey-based news choices. For example, this means that individuals selecting Fox News receive a score of 0.78 for that choice, those selecting $M S N B C$ receive a score of -0.81 and those selecting $C N N$ receive a score of -0.27 . Alignment scores for the expert sources are unavailable in this data, so we code them as 0.

When we examine the relationship between media choice in the survey and behavior outside it, the correspondence remains similar using these alternative outcome measures $(r=0.60$ for Alternative 1 and $r=0.63$ for Alternative 2).

Figure C1 displays the relationship between news choice online and in the survey using these two alternatives. As in the analysis presented in the main text, and even with this change in how media choice in the surveys is coded, there is a relatively high correspondence between the partisanship of an individual's news selections in the two settings. 
Figure C1: Partisan Slant of Survey and Real-World News Choice (Alternative Outcomes)
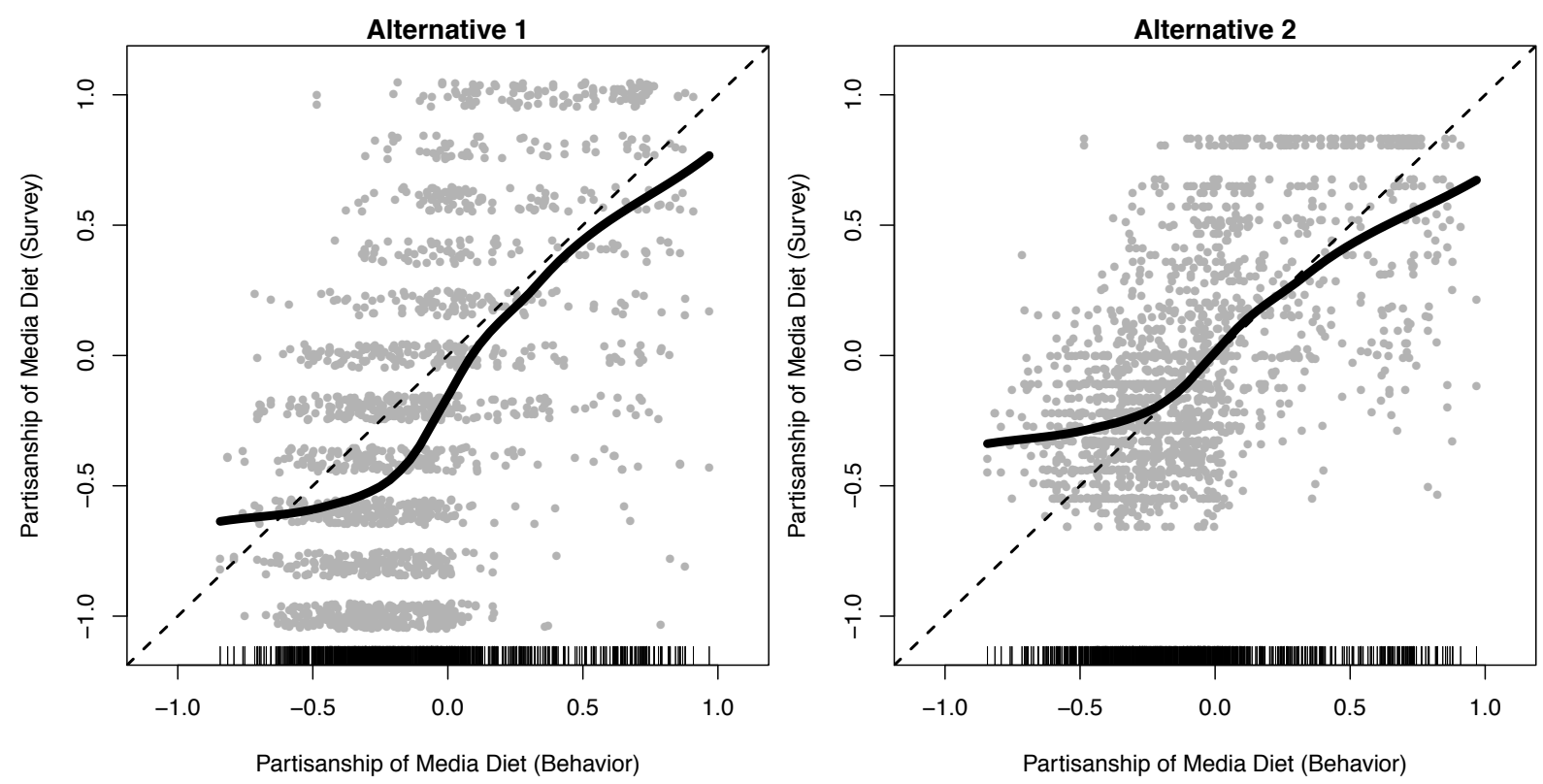

Finally, we consider the partisan divide in news choice across these different settings using the two alternative codings of survey-based news choice.

Table C2: Partisan Divides in Media Choice By Setting (Alternative DV Codings)

\begin{tabular}{l|c|c} 
Setting & Partisan Divide (Alt 1) & Partisan Divide (Alt 2) \\
\hline Survey + No Incentives & $1.35 \mathrm{SD}$ & $1.37 \mathrm{SD}$ \\
Survey + Incentives & $1.36 \mathrm{SD}$ & $1.39 \mathrm{SD}$ \\
Real-World Media Diet & $1.36 \mathrm{SD}$ & $1.36 \mathrm{SD}$
\end{tabular}

As Table C2 indicates, the survey-based divides in news choice using these alternative approaches are similar in magnitude to those in the main text. Altogether, this analysis shows the results in the main text are not an artifact of placing sources with ambiguous or contested reputations into the neutral category. 


\section{C.3 Explaining Survey-Based News Choice}

Below we supplement the plots relating the web-browsing behavior by regressing the partisanship of an individual's survey-based media choices on the partisanship of their web-browsing behavior and the partisanship they reported in the survey. For this we separate out "pure" independents on the 7-pt scale and include leaners with the party they lean towards. The available sample here (840) is slightly smaller than the entire web traffic sample because 15 respondents in the web traffic sample did not visit any of the political websites on our list, meaning we are unable to categorize the partisan slant of their real-world political media exposure.

Table C3: Explaining Partisanship of Survey-Based News Choice

\begin{tabular}{lrrr}
\hline & In-Text DV & Alternative 1 & Alternative 2 \\
\hline (Intercept) & -0.01 & $-0.45^{*}$ & $-0.17^{*}$ \\
& $(0.02)$ & $(0.03)$ & $(0.02)$ \\
Partisanship of Online News Use & $0.31^{*}$ & $0.47^{*}$ & $0.35^{*}$ \\
& $(0.04)$ & $(0.06)$ & $(0.04)$ \\
Independent & $0.16^{*}$ & $0.29^{*}$ & $0.19^{*}$ \\
& $(0.04)$ & $(0.05)$ & $(0.03)$ \\
Republican & $0.37^{*}$ & $0.61^{*}$ & $0.39^{*}$ \\
& $(0.03)$ & $(0.04)$ & $(0.03)$ \\
\hline$N$ & 840 & 840 & 840 \\
\hline Reference category for partisanship is "Democrat" & & \\
Standard errors in parentheses & & & \\
$*$ indicates significance at $p<0.05$ & & &
\end{tabular}

Here the partisanship of an individual's online news use remains a strong predictor of the partisanship of the choices they make inside the survey. 